\title{
ENDOGENOUS POLICY LEADS TO INEFFICIENT RISK SHARING*
}

\author{
Marco Celentani, José-Ignacio Conde-Ruiz ${ }^{\ddagger}$ and Klaus Desmet ${ }^{\S}$
}

MARCH 2003

\footnotetext{
*Marco Celentani gratefully acknowledges the financial support of MCYT (Spain) under project PB98-00024. Klaus Desmet acknowledges the financial support of the Commission for Cultural, Educational and Scientific Exchange between the United States of America and Spain (Project 7-42) and the Comunidad de Madrid (Project 06-0058-2001). We thank Michele Boldrin, Vincenzo Galasso, Berthold Herrendorf, Andy Neumeyer and Ignacio Ortuño Ortín for useful discussions and suggestions. A previous version of this paper was circulated with the title "Incomplete interregional risk sharing with complete markets".

${ }^{\dagger}$ Department of Economics, Universidad Carlos III de Madrid, Getafe (Madrid) 28903, Spain; fax +34-91-624 9875; celentan@eco.uc3m.es.

${ }^{\dagger}$ FEDEA, Calle Jorge Juan 46, 28001 Madrid, Spain; fax +34-91-577 9575; conde - ruiz@fedea.es.

${ }^{\S}$ Department of Economics, Universidad Carlos III de Madrid, Getafe (Madrid) 28903, Spain, and CEPR; fax +34-91-624 9875; desmet@eco.uc3m.es.
} 
ABSTRACT: We analyze risk sharing and endogenous fiscal spending in a two-region model with sequentially complete markets. Fiscal policy is determined by majority voting. When policy setting is decentralized, regions choose pro-cyclical fiscal spending in an attempt to manipulate security prices to their benefit. This leads to incomplete risk sharing, despite the existence of complete markets and the absence of aggregate risk. When a fiscal union centralizes fiscal policy, security prices can no longer be manipulated and complete risk sharing ensues. If regions are relatively homogeneous, median income residents of both regions prefer the fiscal union. If they are relatively heterogeneous, the median resident of the rich region prefers the decentralized setting. KEYWORDs: endogenous policy, complete markets, efficiency, risk sharing JEL classification numbers: C72, D50, D72, E61. 


\section{INTRODUCTION}

It is well known that in the absence of policy distortions sequentially complete markets are sufficient to ensure efficiency in multiperiod economies in which uncertainty resolves gradually over time (Arrow, 1964; Kreps, 1982). In this paper we show how the introduction of endogenous policy in such an environment may undermine efficiency. Our general purpose is to argue that in an economy in which heterogenous agents can gain from trading, but can only do so in sequentially complete markets, endogenous policy setting leads to inefficient equilibrium allocations. We do this by showing that in a two-region model fiscal policy can and will be used to manipulate the future terms of trade of securities, leading to inefficient risk sharing.

The possibility of distorting prices arises because with sequentially complete markets trading takes place at different dates. This implies that no matter when fiscal policy is set, it is always able to affect - and distort - future security prices. For the sake of simplicity we focus on a stylized model with just one trading date, in which fiscal policy is decided prior to trading. In the appendix we show that the intuition for our results in this simplified setting carries over to an economy with trading at multiple dates.

We study a two-region endowment economy. Endowments are subject to shocks. There are two states of nature. In one of the states the endowments of residents in the first region receive a positive multiplicative shock, and the endowments of residents in the second region experience a negative multiplicative shock. In the other state the opposite happens. There is no aggregate uncertainty. Prior to trading taking place, fiscal policy is independently set in each region by majority voting. Each region's fiscal policy specifies a proportional tax rate for each state of nature. Tax revenue is used to finance local public spending. Once fiscal policies have been specified, agents share risk by trading securities in complete markets. After observing the shock, securities are redeemed, and agents consume.

The main result is that decentralized endogenous fiscal policy distorts private risk sharing. Since tax rates are set before agents trade in security markets, they can be used to affect security prices, an incentive we refer to as the manipulation motive. In particular, setting a high (low) level of fiscal spending in a given state decreases (increases) the net supply of securities making a payment in that state. This allows regions to distort fiscal spending in order to improve their terms of trade in securities. As a result, we get incomplete risk sharing, despite the existence of complete markets and the absence of aggregate risk.

This leads to a second result: federal fiscal policy may provide a solution to the fiscal externality problem created by strategic tax setting in a decentralized system. When regions form a fiscal union, the absence of aggregate uncertainty implies there is only one state of nature at the federal 
level. It therefore seems sensible to assume there to be only one tax rate, regardless of which region receives the positive shock. This eliminates the possibility of manipulating security prices via fiscal policy, so that we return to complete risk sharing. This suggests that if regions are fairly similar, the median income residents in both regions prefer the fiscal union to the decentralized system: they benefit from full insurance, while inter-regional net transfers remain limited. However, if regions are relatively different, the median income resident in the region which experiences the positive shock with higher probability is likely to prefer the decentralized system: the benefits from increased risk sharing in the fiscal union do not compensate for the higher net transfers to the other region and for the cost of a less preferred tax rate.

Another way of getting rid of distortions in our simple framework would be to set policy after trading. However, reversing the timing would be of no avail in a multiperiod economy with sequential trading. To see this, consider a dynamic economy with the timing reversed: fiscal policy is set after agents trade risk. In each period there are two states of nature, and two securities, so that markets are sequentially complete. At the beginning of each period, agents share risk by trading securities. Subsequently tax rates are set. In spite of the reverse timing, the manipulation motive survives in this multiperiod setting. Even though fiscal policy in any given period is unable to affect the terms of trade for that same period, it has an impact on individual savings decision and can therefore distort the future terms of trade in security markets. Consequently, the distortions in an economy with sequentially complete markets have nothing to do with the exact timing of fiscal policy. The timing of our simple model is therefore nothing more than a convenient way of illustrating a more general effect in a multiperiod economy.

As mentioned in the beginning, this paper is related to the literature on sequential trading. In the absence of policy distortions, the equilibrium allocations in economies with sequentially complete markets coincide with those in Arrow-Debreu economies, in which all individual risk is traded away upfront through a complete set of dated and state-contingent securities. We make the point that this is no longer the case once we introduce endogenous policy setting.

Because of its focus on interregional risk sharing, our paper also connects with the existing work on fiscal transfers between regions. Such transfers have typically been justified as a risk sharing device against asymmetric shocks when private capital markets are inexistent or incomplete (Persson and Tabellini, 1996a; Alesina and Perotti, 1995). By assuming sequentially complete markets, one might expect fiscal policy to become fully decentralized. Since complete risk sharing could be ensured through private capital markets, there would in principle be no need for interregional transfers. However, we show that decentralized fiscal policy distorts efficient risk sharing. As a result, sequentially complete markets need not imply complete risk sharing, nor need they make fiscal unions redundant. 
The use of fiscal policy to manipulate the terms of trade is the topic of a larger literature (see Persson and Tabellini, 1995, for a survey). The most closely related paper is Devereux and Lee (1999) who, contrary to our results, find that international financial markets weaken the incentive to distort the relative price of exportables. The crucial assumption in their model is that tariffs are set after agents trade in financial markets. Financial contracts are written in terms of commodities. This implies that at the time tariffs are set, agents have not only hedged risk, they have also exhausted all gains from commodity trade. As a result, tariffs are rendered ineffective as a manipulation device. In contrast, in our model fiscal policy is set before security trading, giving rise to manipulation. However, reversing the sequencing is not the only reason for reversing the results of Devereux and Lee (1999). As suggested before, the distortionary effect of decentralized fiscal policy goes through in multiperiod economies, regardless of the sequencing. ${ }^{1}$

Despite the difference in approach, our findings are also reminiscent of the work by Persson and Tabellini (1996b) on risk sharing and moral hazard. They show how decentralized policies lead to inefficient interregional risk sharing, because local governments underinvest in risk reducing policies after a federal risk-sharing agreement has been signed. Abstracting from the effect of regional policies on risk, our paper instead assumes that interregional risk sharing takes place through competitive private markets. In such a setting decentralized fiscal policies can only affect risk sharing if set before private risk-sharing arrangements take place in securities markets.

The rest of the paper is organized as follows. Section 2 introduces the model. Section 3 analyzes the equilibrium for the decentralized case. Section 4 considers the case of a fiscal union and compares it to the decentralized case. Section 5 summarizes and concludes. Appendix A extends our model to a two-period setting and Appendix B provides the proofs of all propositions.

\section{Setup of the Model}

Consider two regions, West and East. We will mainly focus on the West, and we will denote variables referring to the East by an asterisk ("**). Each region has a unit mass of heterogeneous individuals, whose types $y$ are distributed according to the same cumulative distribution function $G(y)$ with mean $\bar{y}$ and median $y^{m} .^{2}$

There is no aggregate risk at the federal level, though each region is subject to perfectly negatively correlated shocks. This gives us two states of nature which we label with respect to the West: if the West experiences a positive shock and the East is hit by a negative shock, we are in the good state $(s=\gamma)$; if, instead, the West receives a negative shock and the East a positive

\footnotetext{
${ }^{1}$ Although Devereux and Lee (1999) also extend their model to the infinite horizon case, they do not allow for borrowing or saving across periods, so that there is no link between different periods.

${ }^{2}$ We assume the same distribution of type for the two regions only to simplify notation but all our results are valid with different type distributions.
} 
shock, we are in the bad state $(s=\beta)$. The probability of the good state is denoted by $\pi$. For notational convenience, variables are indexed by $\gamma$ or $\beta$, depending on which state they refer to.

An individual from the West with type $y$ has endowment $y(1+\varepsilon)$ in the good state and endowment $y(1-\varepsilon)$ in the bad state, with $\varepsilon \in(0,1)$. Similarly, an individual from the East with type $y$ has endowment $y(1-\varepsilon)$ in the good state and endowment $y(1+\varepsilon)$ in the bad state. This stochastic structure provides a simple framework to study risk sharing between regions. Assuming less-than-perfect positive correlation within regions or less-than-perfect negative correlation across regions would complicate the algebra without leading to qualitatively different results.

There is only one commodity that can either be consumed or transformed into a publicly provided good at a constant marginal cost of 1 (in terms of the commodity). Fiscal policy is nondiscriminatory: publicly provided goods are consumed in equal quantities by all individuals of a same region.

We assume the utility function is separable in private consumption $c$ and public consumption $g:$

$$
U(c, g)=V(c)+W(g)
$$

We make the following additional assumptions on preferences:

Assumption $1 \quad$ 1. $V($.$) is twice continuously differentiable, it is homogeneous and$

$$
V^{\prime}(.)>0, V^{\prime \prime}(.)<0
$$

2. $W($.$) is twice continuously differentiable and$

$$
W^{\prime}(.)>0, W^{\prime \prime}(.)<0 \text {. }
$$

The strict inequalities on $V^{\prime \prime}($.$) and W^{\prime \prime}($.$) reflect aversion to private and public consumption$ risk. The separability of the utility function implies that the marginal rate of substitution between private consumption in different states of nature is independent of government consumption, so that efficient risk sharing leads to private consumption being constant across states whenever there is no aggregate uncertainty in disposable income. Moreover, the homogeneity of $V($.$) , together$ with the separability of $U($.$) , implies that an equilibrium exists despite the multidimensionality$ of fiscal policies.

To insure themselves against regional shocks, individuals trade in "elementary securities," each paying one unit of endowment in one state of nature, and zero in the other (Arrow, 1964). We assume that an elementary security exists for each of the two states of nature, so that markets are complete. From now on, we will refer to the elementary security making a unit payment in state $s$ as security $s$. 
Government spending is decided under majority rule and is financed through proportional taxation. Since we only consider one period, governments maintain balanced budgets. To keep the algebra tractable, we take the tax base to be the endowment gross of the payments of securities; in other words, gains or losses deriving from security trades are tax exempt. ${ }^{3}$ Note that the qualitative results would not change if the tax base were to be net, rather than gross, endowment. ${ }^{4}$

Our aim is to study how decentralized fiscal policy distorts risk sharing. In particular, if fiscal policy is set at a time when agents can still gain from sharing risk, it can be used to manipulate security prices, causing incomplete risk sharing. In our simple model we are therefore interested in the following timing of events: fiscal policy is decided under majority rule before individuals trade in elementary securities. To highlight the distortions, we compare our results to a benchmark case, in which fiscal policy is set after agents trade in securities. Under this alternative timing, the manipulation motive disappears, and we get complete risk sharing.

While this seems to suggest that reversing the timing solves the problem, this is only true in the simplified environment we focus on. In a multiperiod economy which requires trading at multiple dates, distortions arise as long as fiscal policy is set before some trading date. In Appendix A we propose a two-period model where agents trade securities at the beginning of each period, and fiscal policy is set after trading. As already explained in the introduction, the manipulation motive survives. Although policy in period 1 is unable to affect security prices in period 1, it can still affect - and distort — security trading in period 2.

Note that we define complete risk sharing as a situation in which risk in both private and public consumption is efficiently shared. Since individuals can hedge risk by trading in security markets, risk in disposable income is always efficiently shared. However, for risk sharing to be complete, risk in government spending must also be shared efficiently. Given that aggregate endowment is constant across states, complete risk sharing therefore requires both private and public consumption to be constant across states.

\section{Risk Sharing with Decentralized Fiscal Policy}

In this section there is no federal government: fiscal policies are set at the regional level and implemented by regional governments. Since constraining the tax rate to be constant across states of nature would introduce an inefficiency by hampering risk sharing, we allow tax rates to be contingent on the state of nature. This implies that fiscal policy in each region is defined by

\footnotetext{
${ }^{3}$ This somewhat extreme assumption could be justified by the observation that capital gains in most countries are taxed at a lower rate than other forms of income. Moreover, it is well known that the effective tax rate on capital gains is in fact lower than the official one, because taxes are paid upon the realization of gains, rather than accrual. See, e.g., Atkinson and Stiglitz (1987, page 116).

${ }^{4}$ Results for this case are available from the authors upon request.
} 
two tax rates: one for the good state, and another for the bad state.

We define the risk sharing game as the game where individuals trade securities and the policy game as the game in which fiscal policies are set under majority rule. As mentioned before, we will consider two timings:

- The manipulation game: the policy game takes place before the risk sharing game.

- The benchmark game: the policy game takes place after the risk sharing game.

Given that we will be interested in characterizing subgame perfect Nash equilibria of these games, the next two subsections will define and characterize the equilibrium of the risk sharing game (subsection 3.1) and the policy game (subsection 3.2). These results are then used to analyze the equilibria of the benchmark game (subsection 3.3) and the manipulation game (subsection 3.4). To illustrate the main results, we end by giving a numerical example (subsection 3.5).

\subsection{The Risk Sharing Game: Security Markets Equilibrium}

DEFINITION 1 An equilibrium of the risk sharing game is a security markets equilibrium for a given vector of fiscal policies in the West and the East, $\left(t_{\gamma}, t_{\beta}, t_{\gamma}^{*}, t_{\beta}^{*}\right)$.

This definition applies to both the manipulation and the benchmark game, with the only difference that fiscal policies are either observed or expected. More specifically, in the manipulation game agents observe the tax rates that have been chosen in the policy game before trading. In contrast, in the benchmark game price-taking agents have given expectations over the tax rates that will be set in the subsequent policy game, and perceive that their trading strategies have no impact on those expectations.

Since an equilibrium of the risk sharing game is defined as a security markets equilibrium, we now turn to analyzing security markets. Equilibria in security markets are determined by individual optimality and market clearing conditions, given a pair of state contingent tax rates for each region. Let $c_{\gamma}$ and $c_{\beta}$ denote private consumption in the good and the bad state, and let $x_{\gamma}$ and $x_{\beta}$ represent net demands of securities $\gamma$ and $\beta$. Furthermore, let $P_{\gamma}$ and $P_{\beta}$ denote the prices of the securities, and call $P=P_{\beta} / P_{\gamma}$ the relative price of security $\beta$. We can now write down the optimization problem of an individual from West with type $y$ :

$$
\begin{array}{cl}
\max _{c_{\gamma}, c_{\beta}, x_{\gamma}, x_{\beta}} & \pi\left[V\left(c_{\gamma}\right)+W\left(g_{\gamma}\right)\right]+(1-\pi)\left[V\left(c_{\beta}\right)+W\left(g_{\beta}\right)\right] \\
\text { s.t. } & x_{\gamma}+P x_{\beta} \leq 0 \\
& c_{\gamma} \leq y(1+\varepsilon)\left(1-t_{\gamma}\right)+x_{\gamma} \\
& c_{\beta} \leq y(1-\varepsilon)\left(1-t_{\beta}\right)+x_{\beta}
\end{array}
$$


By Assumption 1 the solution to the previous problem satisfies the constraints with equality as well as the following condition ${ }^{5}$

$$
\frac{(1-\pi) V^{\prime}\left(c_{\beta}\right)}{\pi V^{\prime}\left(c_{\gamma}\right)}=P
$$

Similarly, the solution to the maximization problem of an individual from the East with type $y$ satisfies the constraints with equality as well as the following condition

$$
\frac{(1-\pi) V^{\prime}\left(c_{\beta}^{*}\right)}{\pi V^{\prime}\left(c_{\gamma}^{*}\right)}=P
$$

By combining individual optimality with market clearing conditions we get the following equilibrium conditions:

$$
\begin{aligned}
& z_{\gamma}(P)=\int x_{\gamma}\left(t_{\gamma}, t_{\beta}, y, P\right) d G(y)+\int x_{\gamma}^{*}\left(t_{\gamma}^{*}, t_{\beta}^{*}, y, P\right) d G(y)=0 \\
& z_{\beta}(P)=\int x_{\beta}\left(t_{\gamma}, t_{\beta}, y, P\right) d G(y)+\int x_{\beta}^{*}\left(t_{\gamma}^{*}, t_{\beta}^{*}, y, P\right) d G(y)=0
\end{aligned}
$$

Given that Assumption 1 implies that preferences over lotteries of private consumption are continuous, strictly convex, strongly monotone, and homothetic, there exists a unique security markets equilibrium - and thus a unique equilibrium of the risk sharing game. Further note that since markets are complete, that equilibrium always leads to efficient risk sharing of disposable income.

\subsection{The Policy Game}

The equilibrium of the policy game depends on whether taxes are set before or after security trading:

DEFINITION 2 1. In the manipulation game, with taxes set before security trading, an equilibrium of the policy game is a vector of fuscal policies for the West and the East such that, given the policy of the other region, neither can be beaten by any other fiscal policy under majority rule, when continuation play is defined by the equilibrium of the risk sharing game.

2. In the benchmark game, with taxes set after security trading, an equilibrium of the policy game for given trades in the risk sharing game is a vector of fiscal policies for the West and the East such that, given the policy of the other region, neither can be beaten by any other fiscal policy under majority rule.

\footnotetext{
${ }^{5}$ Notice in particular that Assumption 1 guarantees that the second order condition is satisfied and that the maximum exists and is interior.
} 
Consider an individual from the West with type $y$ and with demands $\left(x_{\gamma}, x_{\beta}\right)$. Depending on whether we are in the manipulation or the benchmark game, these demands should be interpreted as expected or observed. Given the tax base is endowment gross of the payments of securities, the individual's preferred tax rates $\left(t_{\gamma}, t_{\beta}\right)$ will be given by the solution to the following problem:

$$
\begin{aligned}
& \max _{t_{\gamma}, t_{\beta}} \pi {\left[V\left(y(1+\varepsilon)\left(1-t_{\gamma}\right)+x_{\gamma}\right)+W\left(g_{\gamma}\right)\right]+(1-\pi)\left[V\left(y(1-\varepsilon)\left(1-t_{\beta}\right)+x_{\beta}\right)+W\left(g_{\beta}\right)\right] } \\
& \text { s.t. } g_{\gamma}=\bar{y}(1+\varepsilon) t_{\gamma} \text { and } g_{\beta}=\bar{y}(1-\varepsilon) t_{\beta}
\end{aligned}
$$

where $\bar{y}(1+\varepsilon)$ and $\bar{y}(1-\varepsilon)$ are the aggregate endowments in state $\gamma$ and $\beta$.

The following Lemma states that both in the benchmark and the manipulation game it suffices to consider the preferred tax rates of the median type. To see this, note that the only source of heterogeneity among residents of a region is their type $y$. Moreover, the homogeneity of $V($.$) implies that y$ enters linearly in individual expected utilities. This means that individuals' preferences in the bidimensional policy space - two different tax rates - can be mapped into a one-dimensional parameter space, so that the median voter theorem can be applied. ${ }^{6}$ This in turn implies that equilibrium tax rates can be derived by maximizing the expected utility functions of the individuals with the median types of the two regions.

LEMMa 1 Under Assumption 1 in both the manipulation and the benchmark game the equilibrium of the policy game is given by the tax pairs preferred by the individuals with median types in each region.

Proof. See Appendix B.1.

\subsection{The Benchmark Game: Complete Risk Sharing}

We are now ready to look at how the timing matters in our simple model. We start with the benchmark game, where tax rates are decided after trading in security markets.

DEFINITION 3 An equilibrium of the benchmark game is given by tax rates, prices, and allocations of the path of a subgame perfect Nash equilibrium of the benchmark game.

If fiscal policy is set after individuals have exhausted the gains from risk sharing by trading in securities, the equilibrium tax rates in the West $\left(\hat{t}_{\gamma}, \hat{t}_{\beta}\right)$ are given by the solution to (5) for its median type individual: ${ }^{7}$

$$
\begin{aligned}
V^{\prime}\left(y^{m}(1+\varepsilon)\left(1-\hat{t}_{\gamma}\right)+x_{\gamma}\right) y^{m}(1+\varepsilon)-W^{\prime}\left(\bar{y}(1+\varepsilon) \hat{t}_{\gamma}\right) \bar{y}(1+\varepsilon) & =0 \\
V^{\prime}\left(y^{m}(1-\varepsilon)\left(1-\hat{t}_{\beta}\right)+x_{\beta}\right) y^{m}(1-\varepsilon)-W^{\prime}\left(\bar{y}(1-\varepsilon) \hat{t}_{\beta}\right) \bar{y}(1-\varepsilon) & =0
\end{aligned}
$$

\footnotetext{
${ }^{6}$ In this case policy preferences belong to the class of "intermediate preferences." Cf. Grandmont (1978).

${ }^{7}$ Notice that after trading has taken place the preferred fiscal policy of any individual is independent of the fiscal policy of the other region, so that $\left(\hat{t}_{\gamma}^{*}, \hat{t}_{\beta}^{*}\right)$ do not appear in the equilibrium conditions for $\left(\hat{t}_{\gamma}, \widehat{t}_{\beta}\right)$.
} 
where $x_{\gamma}$ and $x_{\beta}$ come from (2) and (3) and are taken as given. Similar first order conditions determine the equilibrium tax rates in the East $\left(\hat{t}_{\gamma}^{*}, \hat{t}_{\beta}^{*}\right)$.

An equilibrium of the benchmark game requires that the expected tax rates used to determine the demand for securities in the risk sharing game correspond to the tax rates determined in the subsequent policy game. The following proposition states that there exists a unique equilibrium of the benchmark game:

Proposition 1 Suppose Assumption 1 is satisfied. There exists a unique equilibrium of the benchmark game. This equilibrium is characterized by:

1. $\widehat{P}=(1-\pi) / \pi$;

2. $\widehat{c}_{\gamma}(y)=c_{\gamma}(y, \widehat{P})=\widehat{c}_{\beta}(y)=c_{\beta}(y, \widehat{P})$ for all $y, \widehat{c}_{\gamma}^{*}(y)=c_{\gamma}^{*}(y, \widehat{P})=\widehat{c}_{\beta}^{*}(y)=c_{\beta}^{*}(y, \widehat{P})$ for all $y$;

3. $\hat{t}_{\gamma}=\hat{t}_{\beta} \frac{1-\varepsilon}{1+\varepsilon}$ and $\hat{t}_{\gamma}^{*}=\widehat{t}_{\beta}^{*} \frac{1+\varepsilon}{1-\varepsilon}$;

4. $\widehat{g}_{\gamma}=\widehat{g}_{\beta}$ and $\hat{g}_{\gamma}^{*}=\widehat{g}_{\beta}^{*}$.

Proof. See Appendix B.2.

The equilibrium conditions in Proposition 1 are easy to understand. Given that fiscal policy is set after trading, it cannot affect the demand functions for securities, and therefore the securities prices. The absence of a manipulation motive and the perfectly negatively correlated regional shocks allow agents to fully insure both private and public consumption. This implies that the tax rate - but not the tax revenue - will be higher in the bad state than in the good state. As a final remark, note that we would get the same outcome if individuals were to vote on government spending, rather than on tax rates. To see this, simply re-write maximization problem (5) in terms of government spending.

\subsection{The Manipulation Game: Incomplete Risk Sharing}

We now turn our attention to the manipulation game, where agents trade securities after taxes are set.

DEFINITION 4 An equilibrium of the manipulation game is given by tax rates, prices, and allocations of the path of a subgame perfect Nash equilibrium of the manipulation game.

To characterize the equilibria of the manipulation game we first obtain the equilibrium demands for securities from the risk sharing game; those security demands, which are a function 
of tax rates, are then substituted into the objective function of the policy game. This means that in the policy game individual agents recognize the effect of taxes on security demands and prices. In particular, they understand that a region's tax policy can be distorted in an attempt to manipulate security prices to their region's benefit.

To see this, consider the equilibrium of the risk sharing game for a given vector of regional fiscal policies $t=\left(t_{\gamma}, t_{\beta}, t_{\gamma}^{*}, t_{\beta}^{*}\right){ }^{8}$ Denote the corresponding equilibrium demands in West and East for security $s$ by $\widetilde{x}_{s}(t, y)$ and $\widetilde{x}_{s}^{*}(t, y)$; likewise denote the equilibrium consumption in state $s$ by $\widetilde{c}_{s}(t, y)$ and $\widetilde{c}_{s}^{*}(t, y)$. Focusing on the West and taking into account the manipulation motive, the preferred tax rates of the median type are determined by the following first order conditions of maximization problem (5):

$$
\begin{array}{r}
\pi\left[V^{\prime}\left(\widetilde{c}_{\gamma}\right) y^{m}(1+\varepsilon)-W^{\prime}\left(\bar{y}(1+\varepsilon) \tilde{t}_{\gamma}\right) \bar{y}(1+\varepsilon)\right]-\pi V^{\prime}\left(\widetilde{c}_{\gamma}\right) \frac{\partial \widetilde{x}_{\gamma}}{\partial t_{\gamma}}-(1-\pi) V^{\prime}\left(\widetilde{c}_{\beta}\right) \frac{\partial \widetilde{x}_{\beta}}{\partial t_{\gamma}}=0 \\
(1-\pi)\left[V^{\prime}\left(\widetilde{c}_{\beta}\right) y^{m}(1-\varepsilon)-W^{\prime}\left(\bar{y}(1-\varepsilon) \tilde{t}_{\beta}\right) \bar{y}(1-\varepsilon)\right]-\pi V^{\prime}\left(\widetilde{c}_{\gamma}\right) \frac{\partial \widetilde{x}_{\gamma}}{\partial t_{\beta}}-(1-\pi) V^{\prime}\left(\widetilde{c}_{\beta}\right) \frac{\partial \widetilde{x}_{\beta}}{\partial t_{\beta}}=0
\end{array}
$$

To simplify, let $\widetilde{P}(t)=\widetilde{P}\left(t_{\gamma}, t_{\beta}, t_{\gamma}^{*}, t_{\beta}^{*}\right)$ denote the equilibrium price ratio as a function of the state contingent tax rates. Given that

$$
\widetilde{x}_{\beta}=-\frac{\widetilde{x}_{\gamma}}{\widetilde{P}}
$$

we can write

$$
\frac{\partial \widetilde{x}_{\beta}}{\partial t_{\gamma}}=-\frac{\frac{\partial \widetilde{x}_{\gamma}}{\partial t_{\gamma}} \widetilde{P}(t)-\widetilde{x}_{\gamma} \frac{\partial \widetilde{P}(t)}{\partial t_{\gamma}}}{(\widetilde{P}(t))^{2}}
$$

Given budget balance

$$
\begin{aligned}
& \tilde{g}_{\gamma}=\bar{y}(1+\varepsilon) \tilde{t}_{\gamma} \\
& \tilde{g}_{\beta}=\bar{y}(1-\varepsilon) \tilde{t}_{\beta}
\end{aligned}
$$

and given (10), we can rewrite (8) and (9) as:

$$
\begin{array}{r}
\pi\left[V^{\prime}\left(\widetilde{c}_{\gamma}\right) y^{m}(1+\varepsilon)-W^{\prime}\left(\widetilde{g}_{\gamma}\right) \bar{y}(1+\varepsilon)\right]-\frac{(1-\pi) V^{\prime}\left(\widetilde{c}_{\beta}\right) \widetilde{x}_{\gamma} \frac{\partial \widetilde{P}(\tilde{t})}{\partial t_{\gamma}}}{(\widetilde{P}(\tilde{t}))^{2}}=0 \\
(1-\pi)\left[V^{\prime}\left(\widetilde{c}_{\beta}\right) y^{m}(1-\varepsilon)-W^{\prime}\left(\widetilde{g}_{\beta}\right) \bar{y}(1-\varepsilon)\right]-\frac{(1-\pi) V^{\prime}\left(\widetilde{c}_{\beta}\right) \widetilde{x}_{\gamma} \frac{\partial \widetilde{P}(\tilde{t})}{\partial t_{\beta}}}{(\widetilde{P}(\widetilde{t}))^{2}}=0
\end{array}
$$

These conditions take into account the effect of tax rates on net demands of securities - and thus on equilibrium prices. ${ }^{9}$

\footnotetext{
${ }^{8}$ Recall that a unique equilibrium of the risk sharing game exists.

${ }^{9}$ When fiscal policy is set after trading, it has no impact on equilibrium prices, so that $\frac{\partial \widetilde{P}(t)}{\partial t_{\gamma}}=\mathbf{0}$ and $\frac{\partial \widetilde{P}(t)}{\partial t_{\beta}}=\mathbf{0}$. Expressions (11) and (12) therefore simplify to (6) and (7).
} 
More specifically, agents prefer a higher price of the security paying a unit of endowment when their region experiences a positive shock, because in equilibrium they are net sellers of these securities. By the same token, agents prefer a lower price of the security corresponding to the state in which their region receives a negative shock, because in equilibrium they are net buyers of these securities. They therefore inflate tax rates — and government spending — whenever their region experiences a positive shock. This reduces the supply of securities, and pushes up their price. They do the opposite whenever their region is hit by a negative shock: by deflating tax rates - and government spending - the demand for securities drops, lowering their price. As stated in the following proposition, this leads to pro-cyclical fiscal spending and incomplete risk sharing.

PROPOSITION 2 Under Assumption 1, the equilibrium of the manipulation game has the following properties:

1. $\tilde{g}_{\gamma}>\tilde{g}_{\beta}$

2. $\tilde{g}_{\gamma}^{*}<\tilde{g}_{\beta}^{*}$

3. There is incomplete risk sharing.

Proof. See Appendix B.3.

In addition to government spending becoming pro-cyclical, under certain conditions average government spending may actually increase. This result is shown in the next proposition for the case where regions are ex ante sufficiently similar. Recall that variables with a hat refer to the equilibrium of the benchmark game and variables with a tilde refer to the manipulation game.

Proposition 3 Suppose Assumption 1 is satisfied and $W^{\prime \prime \prime}() \geq$.0 . Then there exists a $\underline{\pi} \in\left(\frac{1}{2}, 1\right]$ such that if $\pi \in\left[\frac{1}{2}, \pi\right)$ :

1. $\pi \tilde{g}_{\gamma}+(1-\pi) \tilde{g}_{\beta}>\pi \widehat{g}_{\gamma}+(1-\pi) \widehat{g}_{\beta}$

2. $\pi \tilde{g}_{\gamma}^{*}+(1-\pi) \tilde{g}_{\beta}^{*}>\pi \hat{g}_{\gamma}^{*}+(1-\pi) \hat{g}_{\beta}^{*}$

Proof. See Appendix B.4.

Notice that decreasing absolute risk aversion implies $W^{\prime \prime \prime}() \geq$.0 , a sufficient — though not necessary - condition for the results of Proposition 3 to hold.

Proposition 2 stated that regional fiscal spending is higher when a region experiences a positive shock than when it receives a negative shock. Building on the results of Proposition 3, the following corollary says something more: when a region experiences a positive (negative) shock, its tax rate and its fiscal spending are higher (lower) in the manipulation game than in the benchmark game. 
Corollary 1 Suppose Assumption 1 is satisfied and $W^{\prime \prime \prime}() \geq$.0 . Then there exists a $\underline{\pi} \in\left(\frac{1}{2}, 1\right]$ such that if $\pi \in\left[\frac{1}{2}, \pi\right)$ :

1. $\tilde{t}_{\gamma}>\hat{t}_{\gamma}, \tilde{t}_{\beta}<\hat{t}_{\beta}$

2. $\widetilde{t}_{\beta}^{*}>\hat{t}_{\beta}^{*}, \widetilde{t}_{\gamma}^{*}<\hat{t}_{\gamma}^{*}$;

3. $\tilde{g}_{\gamma}>\hat{g}_{\gamma}=\widehat{g}_{\beta}>\tilde{g}_{\beta}$;

4. $\tilde{g}_{\beta}^{*}>\widehat{g}_{\beta}^{*}=\widehat{g}_{\gamma}^{*}>\widetilde{g}_{\gamma}^{*}$.

We have argued that in an attempt to affect security prices, the West increases government spending in the good state relative to the bad state. But of course the opposite happens in the East, so that the net effect on security prices may be quite small. In fact, when regions are completely symmetric $(\pi=0.5)$, security prices do not change at all. This does not imply complete risk sharing though, as government spending remains inefficient and different across states.

As already mentioned before, the distortions in this stylized economy generalize to a multiperiod economy with sequential trading, independently of the exact timing of fiscal policy. Indeed, if risk sharing requires trading securities at multiple dates, then no matter when fiscal policy is set, it will always be before some future trading date, so that it can be used to affect future security prices.

\subsection{An Example}

To illustrate our results, we now turn to a numerical example. We consider utility function $U(c, g)=\frac{c^{1-\lambda}}{1-\lambda}+\theta \frac{g^{1-\mu}}{1-\mu}$, with $\lambda=2, \mu=2$ and $\theta=1 / 3$. The size of regional shocks $\varepsilon$ is set to 0.2 . We furthermore assume that the type of individuals is distributed according to a generalized uniform distribution function $F(y)=\left(\frac{y}{y_{\max }}\right)^{m}$ on $\left(0, y_{\max }\right]$, with $y_{\max }=1$ and $m=0.7$. This gives a mean type of 0.4118 , a median type of 0.3715 and a median to mean ratio of 0.9 .

As we hinted before, given that both regions try to manipulate security prices in opposite directions, the net effect on prices may be limited. Here we focus on an example where the change in the price ratio ranges from $0 \%$ when $\pi=0.5$ to slightly more than $3 \%$ when $\pi$ is far from 0.5 (Figure 1). 


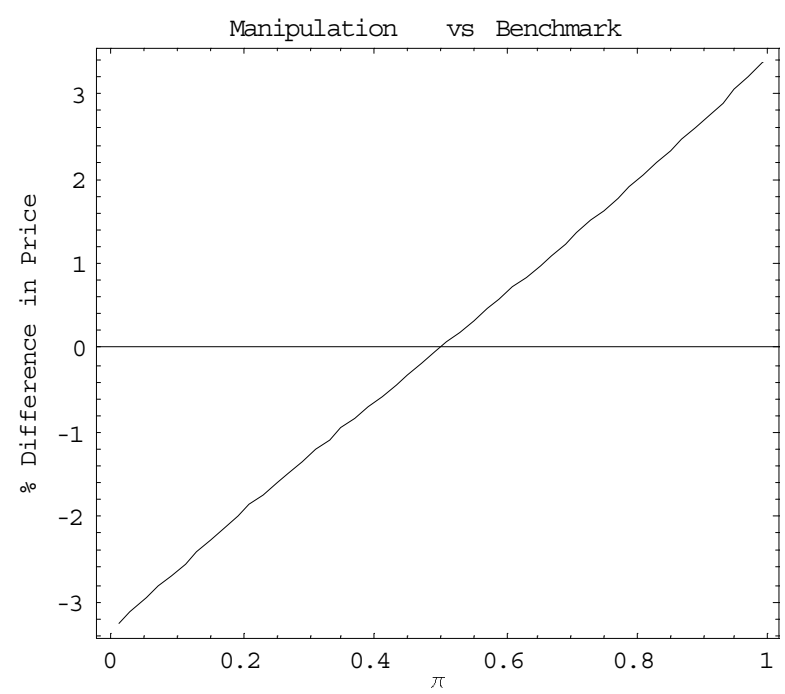

Figure 1: Percentage price difference between manipulation game and benchmark game
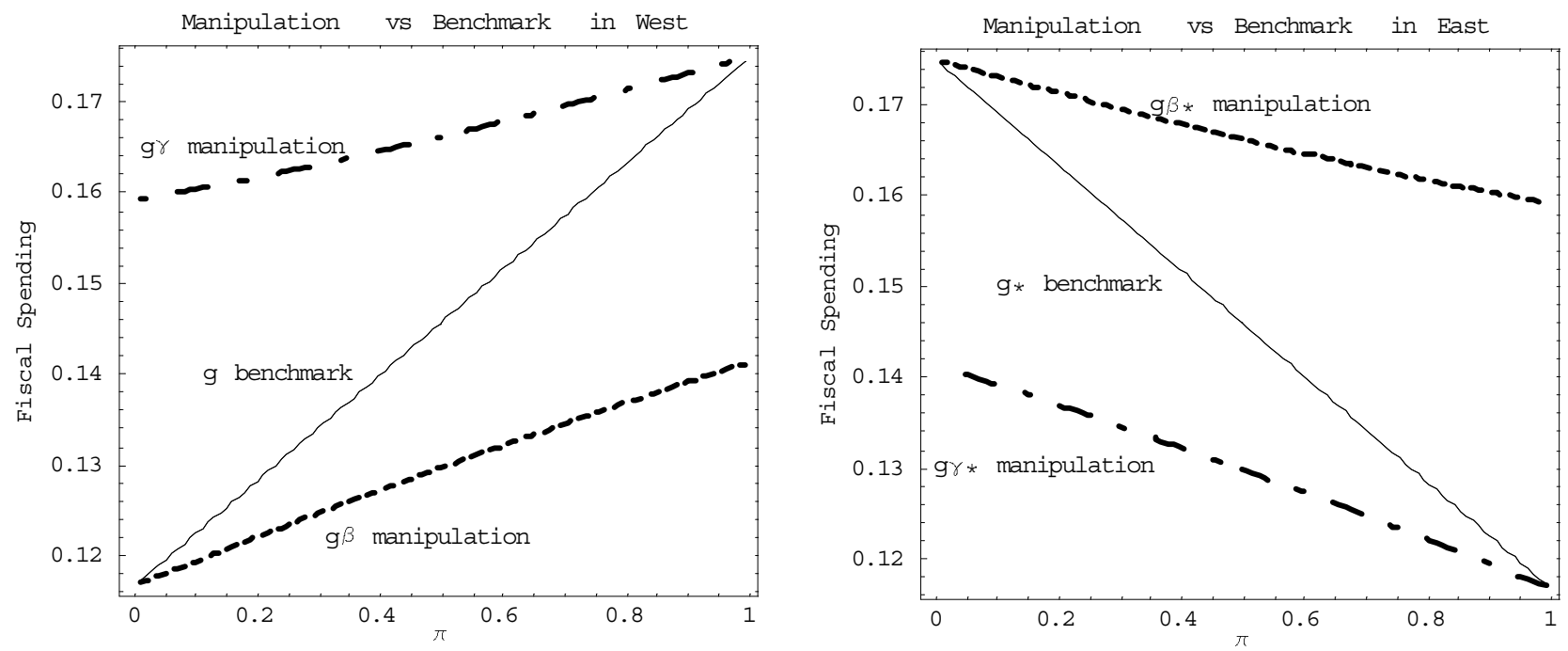

Figure 2: Fiscal spending in West and East.

Figure 2 plots government spending in West and East as a function of $\pi$, the probability of the West receiving the positive shock. By comparing with the equilibrium of the benchmark game, we highlight how the manipulation motive affects fiscal spending. In the equilibrium of the benchmark game (the thin line in Figure 2) fiscal spending is equal across states of nature to ensure complete risk sharing. As suggested by Corollary 1, in the manipulation game fiscal spending is inflated in the good state (the semi-continuous thick line) and deflated in the bad state (the dashed thick line): $\widetilde{g}_{\gamma}>\widehat{g}_{\gamma}=\widehat{g}_{\beta}>\widetilde{g}_{\beta}$; and $\widetilde{g}_{\beta}^{*}>\widehat{g}_{\beta}^{*}=\widehat{g}_{\gamma}^{*}>\widetilde{g}_{\gamma}^{*}$, for $\pi \in(0,1)$. 


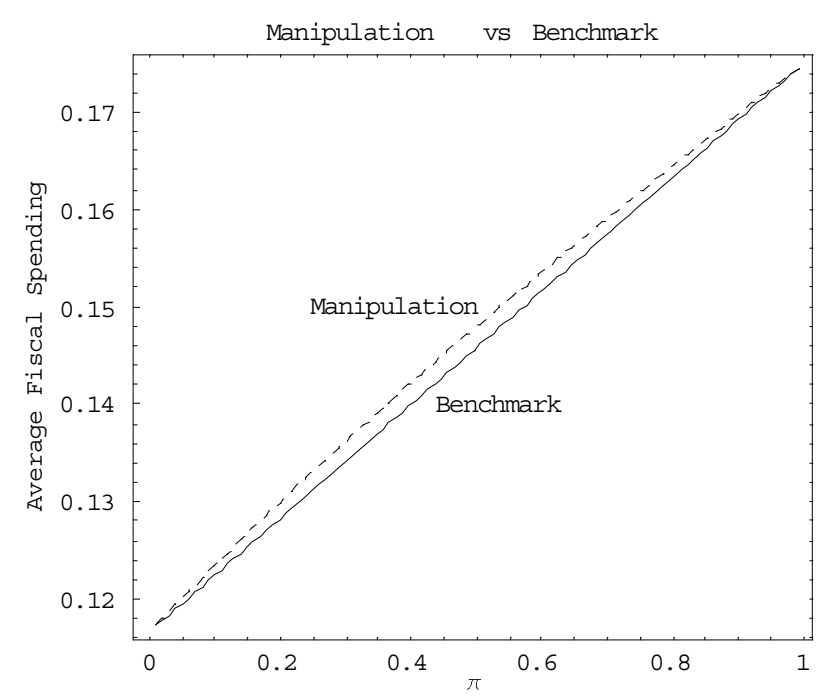

Figure 3: Expected fiscal spending in West.

Figure 3 plots expected government spending in the West, comparing the equilibrium of the manipulation game (the dashed line) to that of the benchmark game (the thin line). As suggested by Proposition 3, the manipulation motive leads to an increase of expected fiscal spending: $\tilde{g}=$ $\pi \tilde{g}_{\gamma}+(1-\pi) \tilde{g}_{\beta}$ is greater than $\hat{g}=\pi \widehat{g}_{\gamma}+(1-\pi) \widehat{g}_{\beta}$.

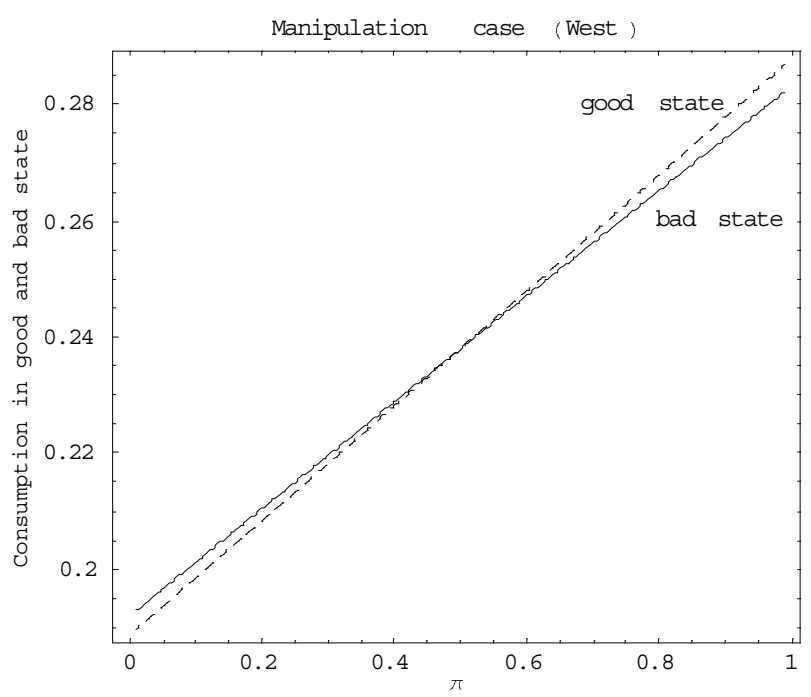

Figure 4: Consumption in good and bad state in the West.

Pro-cyclical fiscal policy does not only lead to incomplete risk sharing in public spending, it also affects private risk sharing. To have complete risk sharing in private consumption, the sum of fiscal spending in West and East must be equal across states of nature: only then will there be no uncertainty in aggregate disposable income. In the manipulation game pro-cyclical fiscal 
spending tends to lead to uncertainty in aggregate disposable income, and thus to incomplete risk sharing in private consumption. This can be seen in Figure 4, where we plot private consumption in the West in the good and the bad state. Note that we only get complete risk sharing in private consumption when $\pi=0.5$. The reason is obvious: when regions are completely symmetric, aggregate government spending — and therefore aggregate disposable income - are constant across states. ${ }^{10}$

Though in the analytical part we have not explicitly talked about welfare, the presumption is that the distortion of security prices, with the corresponding drop in risk sharing, is welfare decreasing. This point is illustrated by Figure 5, where we plot the expected welfare difference between the benchmark and the manipulation game for the median type individual in the West. Not surprisingly, the difference in expected utility is largest at $\pi=0.5$, where uncertainty is maximized. This is of course where the scope for risk sharing - and thus the possibility of distorting security markets - is largest.

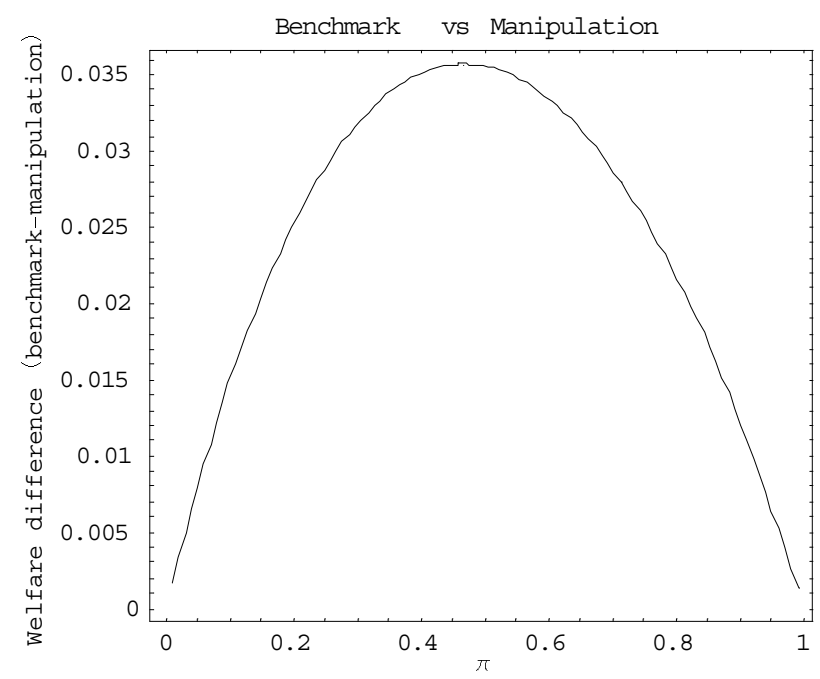

Figure 5: Difference between benchmark and manipulation game expected equilibrium utility for the median type Western resident

\section{Risk Sharing and Fiscal Policy in a Fiscal Union}

We now show how a fiscal union may provide a solution to the distortionary effects of decentralized fiscal policy. As a defining feature of our fiscal union, we assume equal tax rates and equal spending across regions. This is in line with Persson and Tabellini (1996a) who observe that federal constitutions often require residents in different regions to be treated equally. In addition, since there is no aggregate uncertainty in our model, we are left with only one relevant state of

\footnotetext{
${ }^{10}$ When $\pi=0.5$, perfect symmetry implies that $\tilde{g}_{\gamma}=\tilde{g}_{\beta}^{*}$ and $\tilde{g}_{\beta}=\tilde{g}_{\gamma}^{*}$, so that $\widetilde{g}_{\gamma}+\tilde{g}_{\gamma}^{*}=\widetilde{g}_{\beta}+\tilde{g}_{\beta}^{*}$.
} 
nature at the federal level. As a result, there will only be one tax rate, so that fiscal policy can no longer be used to manipulate security prices.

The elimination of this manipulation motive presents clear benefits, since complete insurance now arises even when fiscal policy is set before trading in security markets. In that sense regions stand to gain from forming a fiscal union. But there is a second effect that needs to be taken into account when regions are ex ante different: a common level of spending with a same tax rate implies redistribution across regions, so that the region which is richer in expected terms is likely to benefit less from a fiscal union.

To formalize this intuition, we analyze the case where federal fiscal policy is set before security trading. We start by looking at the risk sharing game, and work our way backward. In the absence of aggregate uncertainty, there is a unique tax rate $\tau$ and a constant tax base $2 \bar{y}$. This implies constant aggregate fiscal spending, and thus constant aggregate disposable income. This, in its turn, leads to constant private consumption across states in the risk sharing game. For an individual from the West with type $y$ equilibrium private consumption can be written as:

$$
\widetilde{c}_{\gamma}(y, \tau)=\widetilde{c}_{\beta}(y, \tau)=\widetilde{c}(y, \tau)=y(1+\varepsilon(2 \pi-1))(1-\tau)
$$

We now turn to the policy game. Fiscal spending per region is constant, and equal to $\tau \bar{y}$. Since both private and public consumption are constant across states, we have complete risk sharing. The preferred tax rate of an individual from the West with type $y$ is the solution to:

$$
\max _{\tau} \pi[V(\widetilde{c}(y, \tau))+W(\tau \bar{y})]+(1-\pi)[V(\widetilde{c}(y, \tau))+W(\tau \bar{y})]
$$

This gives us the following first order condition:

$$
\frac{(1+\varepsilon(2 \pi-1)) V^{\prime}(\tilde{c}(y, \tau))}{W^{\prime}(\tau \bar{y})}=\frac{\bar{y}}{y}
$$

Similarly, the first order condition that determines the preferred tax rate of an individual from East with type $y$ is:

$$
\frac{(1-\varepsilon(2 \pi-1)) V^{\prime}\left(\widetilde{c}^{*}(y, \tau)\right)}{W^{\prime}(\tau \bar{y})}=\frac{\bar{y}}{y}
$$

Given preferences are single peaked, the equilibrium tax rate $\tau$ is the one preferred by the union's median voter. Let $\Gamma(\tau, \pi)$ denote the fraction of individuals in West whose preferred tax rate is less than or equal to $\tau$ and let $\Gamma^{*}(\tau, \pi)$ be the corresponding fraction of individuals in East. The equilibrium tax rate $\tau$ is then given by the solution to:

$$
\Gamma(\tau, \pi)+\Gamma^{*}(\tau, \pi)=1
$$

As mentioned before, whether regions prefer a fiscal union to a decentralized system depends on how similar or how different they are. If regions are quite similar ( $\pi$ close to $1 / 2)$, they will fare 
better under a fiscal union: similar regions suffer the greatest distortions in a decentralized system, so they will reap the largest gains from a fiscal union with perfect risk sharing. However, if regions are relatively different ( $\pi$ far from $1 / 2$ ), the median type in the rich region prefers a decentralized system: the minor risk sharing gains in the fiscal union do not compensate for the cost of a less preferred fiscal policy and the cost of net transfers to the other region. The following proposition formalizes the previous arguments by characterizing individual preferences over the centralized and the decentralized system when regions are sufficiently similar or sufficiently different in ex ante terms.

Proposition 4 Suppose Assumption 1 is satisfied. Then there exist values $\underline{\pi}$, $\bar{\pi}$ with $\frac{1}{2}<\underline{\pi}<$ $\bar{\pi}<1$ such that

1. If $\pi \in\left[\frac{1}{2}, \pi\right)$ (regions are ex-ante similar), at least $50 \%$ of the residents of each region strictly prefer the fiscal union over the decentralized system.

2. If $\pi \in(\bar{\pi}, 1]$ (regions are ex-ante different), at least $50 \%$ of the residents of the West strictly prefer the decentralized system over the fiscal union.

\section{Proof. See Appendix B.5.}

Using the same parameters as before, Figure 6 compares welfare in the decentralized system (dashed line) and the fiscal union (semi-continuous line) for the median income residents in the West and the East. As can be seen, in the vicinity of $\pi=1 / 2$, both median income residents prefer the fiscal union. As regions become increasingly different, this consensus breaks down.
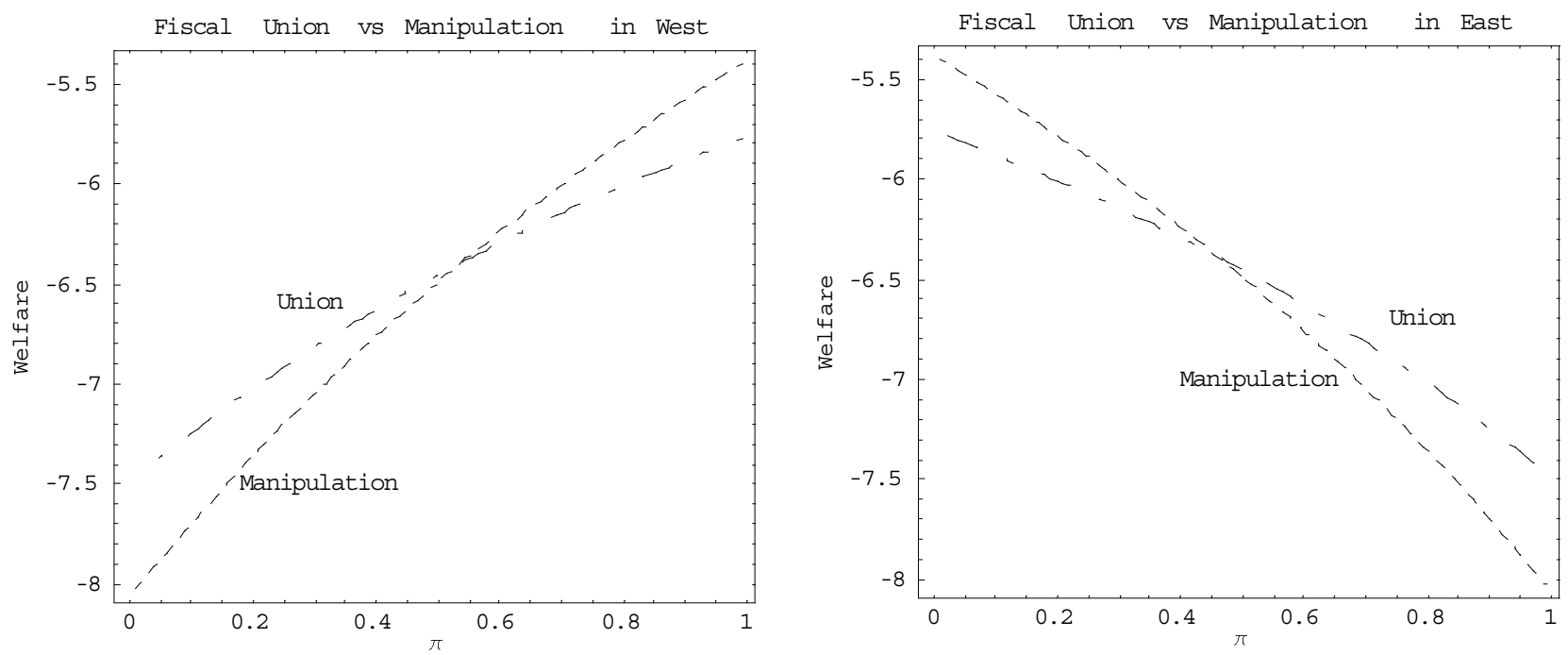

Figure 6: Expected welfare in West and East in fiscal union and in decentralized case. 
Notice that Proposition 4 makes no statement about the preferences of the Eastern median type resident for high values of $\pi$ (or the Western median type resident for low values of $\pi$ ). In fact, this case is ambiguous: it is possible that the fiscal union leads to a higher equilibrium tax rate in the East compared to the decentralized system, so that the benefits of higher public consumption and complete risk sharing could be swept away by too high tax rates, depressing disposable income and private consumption. Although in the particular example of Figure 6 the median type resident of the East prefers the fiscal union to the decentralized system for all values of $\pi$ higher than $1 / 2$, this need not be always the case.

\section{Conclusion}

In this paper we have studied how fiscal policy distorts efficient risk sharing in a two-region model with sequentially complete markets. We have analyzed a simple environment, in which fiscal policy is set before agents trade risk in complete security markets. In an attempt to improve the terms of trade of securities, each region chooses a pro-cyclical fiscal policy, inflating government spending when a positive shock occurs and deflating it when hit by a negative shock. These distortions lead to incomplete risk sharing and higher volatility of government spending.

We have then shown that a fiscal union eliminates such distortions and allows for complete risk sharing. However, if regions are ex ante different in terms of exposure to shocks, a fiscal union also has its costs. It implies net transfers from the region more likely to experience a positive shock to the other region. Moreover, heterogeneity across regions implies that fiscal policy in the union will differ from the one preferred by the median income residents in each region. Summing up, if regions are fairly similar, a majority of residents in each region fares better under the fiscal union; if, however, regions are fairly different, a majority of residents in the rich region continues to prefer the decentralized system.

The decentralized environment we have described is one in which equilibrium allocations would be efficient if individual agents could exhaust all the gains from trade before policies are set. In this case policies would not be used in an attempt to affect equilibrium prices in favor of one constituency or the other. When markets are sequentially complete, however, certain trades can only be realized at future dates. Endogenous policies can then be used in an attempt to distort future prices, so that the ensuing equilibrium allocation is inefficient. The same argument can be extended to other settings. At a more general level, this paper clarifies that in an economy in which heterogenous agents can gain from trading, but can only trade in sequentially complete markets, endogenous policy setting leads to inefficient equilibrium allocations. 


\section{A Manipulation in a tWo-period model}

The example in this appendix illustrates how in a multi-period model with sequentially complete markets the manipulation motive survives, even when fiscal policy is decided after trading. To focus on the simplest possible case, we analyze a two-period two-region model with a representative agent in each region. In each period there are two states of nature. States are independent across periods. Markets are sequentially complete. At the beginning of each period two securities are traded, one for each state of nature.

To keep things simple, we abstract from government spending in the second period. This is not important, because in a two-period model with policy set after trading, the manipulation motive only applies to taxes in the first period. In period 1, after trading has taken place, each region sets its fiscal policy consisting of a pair of tax rates, one for each realization of the shock in that period. Note that the results would not change if fiscal policy were decided after the realization of the shock, because the optimal contingent tax rates set after trading but before the shock coincide with those that would be chosen after observing the shock. In other words, the possibility of manipulating security prices does not depend on the timing of the model.

We allow for savings, so that fiscal policy in the first period can influence security trading in the second period. Indeed, by affecting disposable income in period 2, savings in period 1 can affect the supply - and thus the price - of securities in period 2. This manipulation motive would obviously unravel in a standard Arrow-Debreu world in which all risk is traded away up-front. However, our focus is on sequentially complete markets, in which a limited number of securities needs to be traded at different dates to ensure efficient risk sharing.

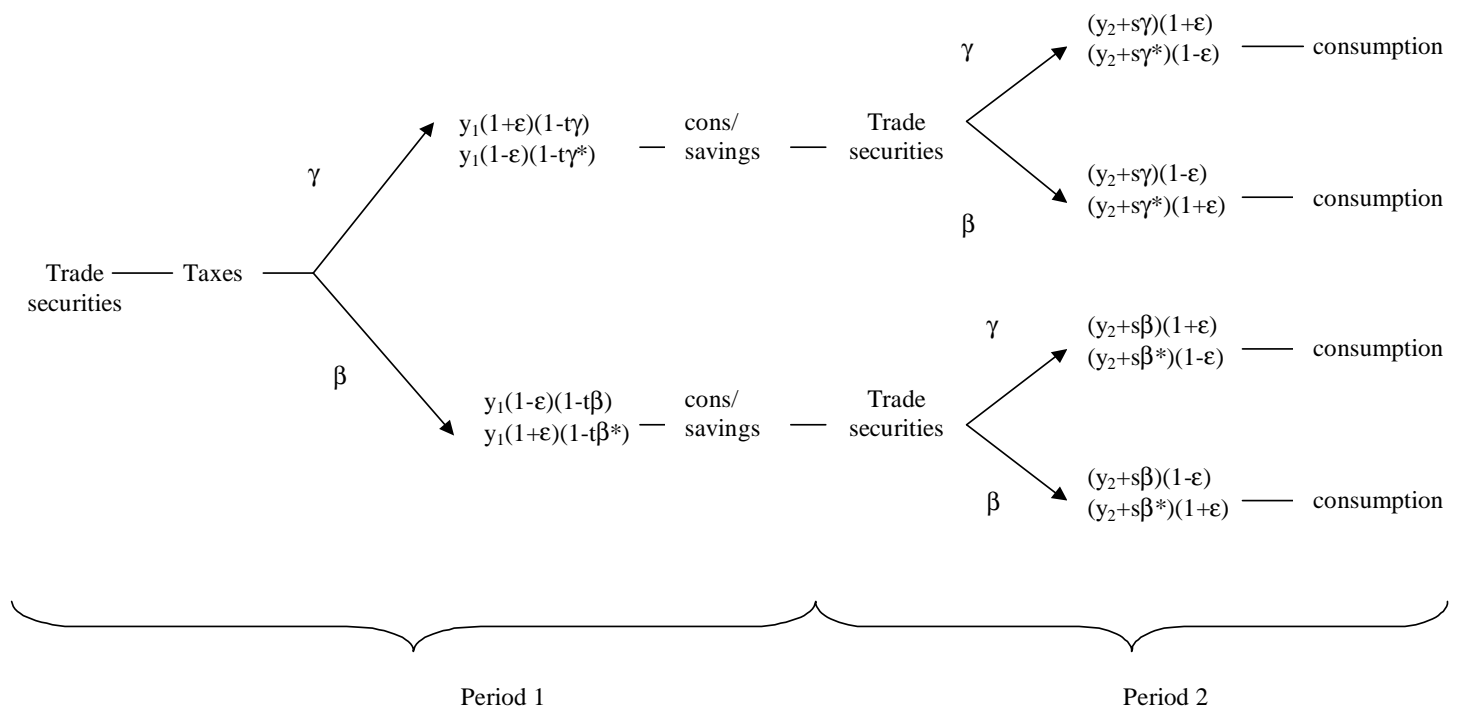

Figure 7: A two-period model. 
Figure 7 summarizes the model. At the beginning of period 1, agents trade securities to hedge against risk in the same period. There are two possible states of nature: in the good state $(s=\gamma)$ West receives $y_{1}(1+\varepsilon)$ and East $y_{1}(1-\varepsilon)$; in the bad state $(s=\beta)$ West gets $y_{1}(1-\varepsilon)$ and East $y_{1}(1+\varepsilon)$. After trading contingent tax rates - and therefore contingent government spending - are set. After the state is realized securities are redeemed, fiscal policy is implemented and agents decide how much to consume and how much to save. At the beginning of period 2 agents reconvene to trade securities and insure themselves against risk in period 2. Once the state of nature is revealed, and the securities are redeemed, they consume.

Note that period 1's savings translate into uncertain future output: for a level of savings $s$ in period 1 , West receives $\left(y_{2}+s\right)(1+\varepsilon)$ in period 2 if the state is good, and $\left(y_{2}+s\right)(1-\varepsilon)$ if the state is bad. Think of a fishing economy. Instead of consuming a fish in period 1 , it could be thrown back into the pond. If we are lucky, the fish multiplies, and we get more than one fish in period 2; if we are unlucky, the fish dies, and we get less than one fish in period 2. Note that our modeling choice is not innocuous: because savings have an uncertain payoff, they increase the scope for risk sharing. This implies that fiscal spending in period 1, through its effect on savings, can be used to manipulate security markets in period 2 .

Before turning to the model, we need to introduce some additional notation. Security ij makes a unit payment in state $i$ of period 2, conditional on $j$ being the state in period 1 . The net demand for security $i j$ is denoted by $x_{i j}$. As for prices, $P_{2 \gamma}$ refers to the price of security $\gamma \beta$ relative to the price of security $\gamma \gamma$, whereas $P_{2 \beta}$ denotes the price of $\beta \beta$ relative to $\beta \gamma$. Finally, $s_{i}$ stands for savings in period 1 when the state of nature is $i$. To keep things simple, we focus on the $\log$ utility function, and set the discount factor equal to 1.

We solve the model backwards, and therefore start by looking at the risk sharing game in the second period. Assuming the state of nature in the first period was $\gamma$, the representative agent's problem of West and East can be written as:

$$
\begin{array}{ll}
\max _{x_{\gamma \beta}} & \pi\left(y_{2}+s_{\gamma}\right)(1+\varepsilon)-P_{2 \gamma} x_{\gamma \beta}+(1-\pi)\left(y_{2}+s_{\gamma}\right)(1-\varepsilon)+x_{\gamma \beta} \\
\max _{x_{\gamma \beta}^{*}} & \pi\left(y_{2}+s_{\gamma}^{*}\right)(1-\varepsilon)-P_{2 \gamma} x_{\gamma \beta}^{*}+(1-\pi)\left(y_{2}+s_{\gamma}^{*}\right)(1+\varepsilon)+x_{\gamma \beta}^{*}
\end{array}
$$

The outcome of (14), combined with the market clearing condition $x_{\gamma \beta}=-x_{\gamma \beta}^{*}$ allows us to solve out for $P_{2 \gamma}$. By analogy, equilibrium values for $x_{\beta \beta}, x_{\beta \beta}^{*}$ and $P_{2 \beta}$ can be obtained if the state of nature in the first period was $\beta$.

We then turn to the savings decision in period 1. Assuming once again that the state of nature in the first period was $\gamma$, the representative agent's problem of West and East takes the following form:

$$
\max _{s_{\gamma}} \log \left(\left(y_{1}+\varepsilon\right)\left(1-t_{\gamma}\right)+x_{\gamma}-s_{\gamma}\right)+\log \left(t_{\gamma} y_{1}(1+\varepsilon)\right)
$$




$$
\begin{array}{ll} 
& +\pi \log \left(\left(y_{2}+s_{\gamma}\right)(1+\varepsilon)-P_{2 \gamma} x_{\gamma \beta}\left(s_{\gamma}\right)\right)+(1-\pi) \log \left(\left(y_{2}+s_{\gamma}\right)(1-\varepsilon)+x_{\gamma \beta}\left(s_{\gamma}\right)\right) \\
\max _{s_{\gamma}^{*}} & \log \left(\left(y_{1}-\varepsilon\right)\left(1-t_{\gamma}^{*}\right)+x_{\gamma}^{*}-s_{\gamma}^{*}\right)+\log \left(t_{\gamma}^{*} y_{1}(1-\varepsilon)\right) \\
& +\pi \log \left(\left(y_{2}+s_{\gamma}^{*}\right)(1-\varepsilon)-P_{2 \gamma} x_{\gamma \beta}^{*}\left(s_{\gamma}^{*}\right)\right)+(1-\pi) \log \left(\left(y_{2}+s_{\gamma}^{*}\right)(1+\varepsilon)+x_{\gamma \beta}^{*}\left(s_{\gamma}^{*}\right)\right)
\end{array}
$$

Note from (15) and (16) that the representative agents take into account the effect of their savings decisions on their demand for securities in period 2 but that, being price-takers, they assume that they cannot affect the relative prices of those securities. By analogy, the equilibrium values for $s_{\beta}$ and $s_{\beta}^{*}$ can be determined if the state of nature in period 1 was $\beta$.

Taking one further step backward, we look at tax setting in period 1 . The tax rates for state $\gamma$ that maximize the representative agents continuation utilities are given by the solution of the following problems for West and East:

$$
\begin{array}{ll}
\max _{t_{\gamma}} & \log \left(\left(y_{1}+\varepsilon\right)\left(1-t_{\gamma}\right)+x_{\gamma}-s_{\gamma}\left(t_{\gamma}\right)\right)+\log \left(t_{\gamma} y_{1}(1+\varepsilon)\right) \\
& +\pi \log \left(\left(y_{2}+s_{\gamma}\left(t_{\gamma}\right)\right)(1+\varepsilon)-P_{2 \gamma}\left(t_{\gamma}\right) x_{\gamma \beta}\left(t_{\gamma}\right)\right) \\
& +(1-\pi) \log \left(\left(y_{2}+s_{\gamma}\left(t_{\gamma}\right)\right)(1-\varepsilon)+x_{\gamma \beta}\left(t_{\gamma}\right)\right) \\
\max _{t_{\gamma}^{*}} & \log \left(\left(y_{1}-\varepsilon\right)\left(1-t_{\gamma}^{*}\right)+x_{\gamma}^{*}-s_{\gamma}^{*}\left(t_{\gamma}^{*}\right)\right)+\log \left(t_{\gamma}^{*} y_{1}(1-\varepsilon)\right) \\
& +\pi \log \left(\left(y_{2}+s_{\gamma}^{*}\left(t_{\gamma}^{*}\right)\right)(1-\varepsilon)-P_{2 \gamma}\left(t_{\gamma}^{*}\right) x_{\gamma \beta}^{*}\left(t_{\gamma}^{*}\right)\right) \\
& +(1-\pi) \log \left(\left(y_{2}+s_{\gamma}^{*}\left(t_{\gamma}^{*}\right)\right)(1+\varepsilon)+x_{\gamma \beta}^{*}\left(t_{\gamma}^{*}\right)\right)
\end{array}
$$

Note from (17) and (18) that the representative agent takes into the account the effect of the tax rates not only on savings, but also on the demand and the price of securities in the second period. In other words, fiscal policy has incentive to manipulate tax levels to affect future security trading. By analogy, the tax rates $t_{\beta}$ and $t_{\beta}^{*}$ can be determined.

Finally, we solve the risk sharing game in period 1 for West and East:

$$
\begin{array}{ll}
\max _{x_{\beta}} & \pi\left[\log \left(\left(y_{1}+\varepsilon\right)\left(1-t_{\gamma}\right)-P x_{\beta}-s_{\gamma}\left(x_{\beta}\right)+\log \left(t_{\gamma} y_{1}(1+\varepsilon)\right)\right]\right. \\
& +(1-\pi)\left[\log \left(\left(y_{1}-\varepsilon\right)\left(1-t_{\beta}\right)+x_{\beta}-s_{\beta}\left(x_{\beta}\right)+\log \left(t_{\beta} y_{1}(1-\varepsilon)\right)\right]\right. \\
& +\pi\left[\pi \log \left(\left(y_{2}+s_{\gamma}\left(x_{\beta}\right)\right)(1+\varepsilon)-P_{2 \gamma} x_{\gamma \beta}\left(x_{\beta}\right)\right)+(1-\pi) \log \left(\left(y_{2}+s_{\gamma}\left(x_{\beta}\right)\right)(1-\varepsilon)+x_{\gamma \beta}\right)\left(x_{\beta}\right)\right] \\
& +(1-\pi)\left[\pi \log \left(\left(y_{2}+s_{\beta}\left(x_{\beta}\right)\right)(1+\varepsilon)-P_{2 \beta} x_{\beta \beta}\left(x_{\beta}\right)\right)\right. \\
& \left.+(1-\pi) \log \left(\left(y_{2}+s_{\beta}\left(x_{\beta}\right)\right)(1-\varepsilon)+x_{\beta \beta}\left(x_{\beta}\right)\right)\right] \\
\max _{x_{\beta}^{*}} & \pi\left[\log \left(\left(y_{1}-\varepsilon\right)\left(1-t_{\gamma}^{*}\right)-P x_{\beta}^{*}-s_{\gamma}^{*}\left(x_{\beta}^{*}\right)+\log \left(t_{\gamma}^{*} y_{1}(1-\varepsilon)\right)\right]\right.
\end{array}
$$




$$
\begin{aligned}
& +(1-\pi)\left[\log \left(\left(y_{1}+\varepsilon\right)\left(1-t_{\beta}^{*}\right)+x_{\beta}^{*}-s_{\beta}^{*}\left(x_{\beta}^{*}\right)+\log \left(t_{\beta}^{*} y_{1}(1+\varepsilon)\right)\right]\right. \\
& +\pi\left[\pi \log \left(\left(y_{2}+s_{\gamma}^{*}\left(x_{\beta}^{*}\right)\right)(1-\varepsilon)-P_{2 \gamma} x_{\gamma \beta}^{*}\left(x_{\beta}^{*}\right)\right)+(1-\pi) \log \left(\left(y_{2}+s_{\gamma}^{*}\left(x_{\beta}^{*}\right)\right)(1+\varepsilon)+x_{\gamma \beta}^{*}\right)\left(x_{\beta}^{*}\right)\right] \\
& +(1-\pi)\left[\pi \log \left(\left(y_{2}+s_{\beta}^{*}\left(x_{\beta}^{*}\right)\right)(1-\varepsilon)-P_{\beta} x_{\beta \beta}^{*}\left(x_{\beta}^{*}\right)\right)\right. \\
& \left.+(1-\pi) \log \left(\left(y_{2}+s_{\beta}^{*}\left(x_{\beta}^{*}\right)\right)(1+\varepsilon)+x_{\beta \beta}^{*}\right)\left(x_{\beta}^{*}\right)\right]
\end{aligned}
$$

As can be seen, in a competitive framework, agents do not take into account the effect of their

\begin{tabular}{|c|c|c|c|c|}
\hline & \multicolumn{2}{|c|}{ West } & \multicolumn{2}{|c|}{ East } \\
\hline & Benchmark & Manipulation & Benchmark & Manipulation \\
\hline \multicolumn{5}{|l|}{ 1. $\pi=0.5$} \\
\hline government spending $(s=\gamma)$ & 0.256 & 0.260 & 0.476 & 0.483 \\
\hline government spending $(s=\beta)$ & 0.476 & 0.483 & 0.256 & 0.260 \\
\hline total utility & -3.2958 & -3.2960 & -3.2958 & -3.2960 \\
\hline \multicolumn{5}{|l|}{ 2. $\pi=0.4$} \\
\hline government spending $(s=\gamma)$ & 0.241 & 0.245 & 0.505 & 0.511 \\
\hline government spending $(s=\beta)$ & 0.448 & 0.455 & 0.272 & 0.275 \\
\hline total utility & -3.5377 & -3.5378 & -3.0675 & -3.0677 \\
\hline \multicolumn{5}{|l|}{ 3. $\pi=0.3$} \\
\hline government spending $(s=\gamma)$ & 0.226 & 0.229 & 0.533 & 0.539 \\
\hline government spending $(s=\beta)$ & 0.419 & 0.426 & 0.287 & 0.290 \\
\hline total utility & -3.7962 & -3.7963 & -2.8502 & -2.8504 \\
\hline
\end{tabular}
decisions on future taxes and prices. The solution to (19) and (20), combined with the market clearing condition $x_{\beta}=-x_{\beta}^{*}$, allows us to solve out for the equilibrium price $P$.

Table 1: Manipulation vs. benchmark in two-period model

We now present a numerical example that illustrates the effect of manipulation in this twoperiod model. To see the distortionary effect, we need to compare to a benchmark case, which is defined as the case where taxes are set by solving (17) and (18) without taking into account their effects on security markets in period 2. Note that manipulation depends on there being savings: this is what leads decisions in period 1 to affect outcomes in period 2. To ensure positive savings, we choose $y_{1}>y_{2}$, more particularly we set $y_{1}=1$ and $y_{2}=0$. The output shock $\varepsilon$ in this example is set equal to 0.3 . As can be seen in Table 1 , in all cases there exists a motive to distort tax rates (and thus government spending). This leads to inefficient risk sharing, and a drop in utility. 


\section{B.1 Proof of Lemma 1}

The proof will only be given for the manipulation game. The proof for the benchmark game follows by analogy.

From (2) the securities demand functions of an individual with type $y$ are such that:

$$
V^{\prime}\left(y(1-\varepsilon)\left(1-t_{\beta}\right)-\frac{x_{\gamma}}{P}\right)=\frac{P \pi}{(1-\pi)} V^{\prime}\left(y(1+\varepsilon)\left(1-t_{\gamma}\right)+x_{\gamma}\right)
$$

If $V(\cdot)$ is homogeneous of degree $r+1, V^{\prime}(\cdot)$ is homogeneous of degree $r$, and it is easy to see that (21) implies

$$
x_{\gamma}=y\left[\frac{(1-\varepsilon)\left(1-t_{\beta}\right)-\left(\frac{P \pi}{(1-\pi)}\right)^{\frac{1}{r}}(1+\varepsilon)\left(1-t_{\gamma}\right)}{\left(\frac{P \pi}{(1-\pi)}\right)^{\frac{1}{r}}+\frac{1}{P}}\right]
$$

so that $x_{\gamma}$ can be rewritten as

$$
x_{\gamma}=y f(t)
$$

where $t=\left(t_{\gamma}, t_{\beta}, t_{\gamma}^{*}, t_{\beta}^{*}\right)$ and $f(t)$ does not depend on $y$. Since from the budget constraint $x_{\beta}=-\frac{x_{\gamma}}{P}$ we also have that

$$
x_{\beta}=-y \frac{f(t)}{P}
$$

Given (22) and (23), indirect expected utility for an individual with type equal to $y$ for a given $t=\left(t_{\gamma}, t_{\beta}, t_{\gamma}^{*}, t_{\beta}^{*}\right)$ can be shown to be equal to

$$
h(t, y)=y^{r+1} k(t)+z(t)
$$

where

$$
\begin{aligned}
& k(t)=\left[\pi V\left(\left((1+\varepsilon)\left(1-t_{\gamma}\right)+f(t)\right)\right)+(1-\pi) V\left(\left((1-\varepsilon)\left(1-t_{\beta}\right)+f(t)\right)\right)\right] \\
& z(t)=\pi W\left(g_{\gamma}\right)+(1-\pi) W\left(g_{\beta}\right) .
\end{aligned}
$$

is common to all individuals.

Consider the following two cases: $r+1 \geq 0$ and $r+1<0$.

1. $r+1 \geq 0$. Let $t=\left(t_{\gamma}, t_{\beta}, t_{\gamma}^{*}, t_{\beta}^{*}\right)$ be such that $\left(t_{\gamma}, t_{\beta}\right)$ is the most preferred fiscal policy of the Western individual with the median type, $y^{m}$, given the Eastern fiscal policy is $\left(t_{\gamma}^{*}, t_{\beta}^{*}\right)$ and let $t^{\prime}=\left(t_{\gamma}^{\prime}, t_{\beta}^{\prime}, t_{\gamma}^{*}, t_{\beta}^{*}\right)$ with $\left(t_{\gamma}^{\prime}, t_{\beta}^{\prime}\right) \neq\left(t_{\gamma}, t_{\beta}\right)$ and otherwise arbitrary. Clearly, $h\left(t, y^{m}\right)-h\left(t^{\prime}, y^{m}\right) \leq 0$. 
Suppose that $k(t)-k\left(t^{\prime}\right) \leq 0$. Then if

$$
h\left(t, y^{m}\right)-h\left(t^{\prime}, y^{m}\right)=\left(y^{m}\right)^{r+1}\left[k(t)-k\left(t^{\prime}\right)\right]+\left[z(t)-z\left(t^{\prime}\right)\right]>0
$$

then there exists a $y^{\prime}>y^{m}$, such that $h(t, y)-h\left(t^{\prime}, y\right)>0$ for any $y \leq y^{\prime}$. It follows from the definition of the median that a majority of voters would prefer $t$ to $t^{\prime}$.

Suppose now $k(t)-k\left(t^{\prime}\right) \geq 0$. Then if

$$
h\left(t, y^{m}\right)-h\left(t^{\prime}, y^{m}\right)=\left(y^{m}\right)^{r+1}\left[k(t)-k\left(t^{\prime}\right)\right]+\left[z(t)-z\left(t^{\prime}\right)\right]>0
$$

then there exists a $y^{\prime}<y^{m}$, such that $h(t, y)-h\left(t^{\prime}, y\right)>0$ for any $y \geq y^{\prime}$. It follows from the definition of the median that a majority of voters would prefer $t$ to $t^{\prime}$.

Because we can repeat the argument for any alternative allocation, $t^{\prime}, t$ is the unique majority winner.

2. A similar argument shows that the same is true when $r+1<0$.

\section{B.2 Proof of Proposition 1}

Suppose that $\widehat{P}=\frac{1-\pi}{\pi}$. First order conditions (2) and (3) imply that $c_{\gamma}(y, \widehat{P})=c_{\beta}(y, \widehat{P})$ for all $y$ and $c_{\gamma}^{*}(y, \widehat{P})=c_{\beta}^{*}(y, \widehat{P})$ for all $y$. From $(6)$ and $(7)$ we get $W^{\prime}\left(\bar{y}(1+\varepsilon) \hat{t}_{\gamma}\right)=$ $W^{\prime}\left(\bar{y}(1-\varepsilon) \hat{t}_{\beta}\right)$, so that $g_{\gamma}=g_{\beta}$ and $\hat{t}_{\gamma}=\hat{t}_{\beta} \frac{1-\varepsilon}{1+\varepsilon}$. By analogy, for East we get $W^{\prime}\left(\bar{y}(1-\varepsilon) \hat{t}_{\gamma}^{*}\right)=$ $W^{\prime}\left(\bar{y}(1+\varepsilon) \hat{t}_{\beta}^{*}\right)$, so that $g_{\gamma}^{*}=g_{\beta}^{*}$ and $\hat{t}_{\gamma}^{*}=\hat{t}_{\beta}^{*} \frac{1+\varepsilon}{1-\varepsilon}$. To prove that $\widehat{P}=\frac{1-\pi}{\pi}$, note that $\widehat{t}_{\gamma}=$ $\hat{t}_{\beta} \frac{1-\varepsilon}{1+\varepsilon}$ and $\hat{t}_{\gamma}^{*}=\hat{t}_{\beta}^{*} \frac{1+\varepsilon}{1-\varepsilon}$ imply that aggregate endowment net of tax revenues is constant across states, so that because of aversion to private consumption risk we have $c_{\gamma}(y, \widehat{P})=c_{\beta}(y, \widehat{P})$ for all $y, c_{\gamma}^{*}(y, \widehat{P})=c_{\beta}^{*}(y, \widehat{P})$ for all $y$.

Suppose now that an equilibrium exists with $\hat{P}>\frac{1-\pi}{\pi}$. First order conditions (2) and (3) imply that $c_{\gamma}(y, \widehat{P})>c_{\beta}(y, \hat{P})$ for all $y$ and $c_{\gamma}^{*}(y, \widehat{P})>c_{\beta}^{*}(y, \widehat{P})$ for all $y$. From $(6)$ and (7) we get $W^{\prime}\left(\bar{y}(1+\varepsilon) \hat{t}_{\gamma}\right)<W^{\prime}\left(\bar{y}(1-\varepsilon) \hat{t}_{\beta}\right)$, so that $g_{\gamma}>g_{\beta}$. By analogy, for East we get $W^{\prime}\left(\bar{y}(1-\varepsilon) \hat{t_{\gamma}^{*}}\right)<W^{\prime}\left(\bar{y}(1+\varepsilon) \hat{t}_{\beta}^{*}\right)$, so that $g_{\gamma}^{*}>g_{\beta}^{*}$ and it is easy to see that the market clearing constraints are violated.

A symmetric argument shows that no equilibrium can exist with $\widehat{P}<\frac{1-\pi}{\pi}$ and completes the proof.

\section{B.3 Proof of Proposition 2}

Denote the tax rates in the equilibrium of the manipulation game by $\tilde{t}=\left(\tilde{t}_{\gamma}, \widetilde{t}_{\beta}, \widetilde{t}_{\gamma}^{*}, \tilde{t}_{\beta}^{*}\right)$ and let $\tilde{g}=\left(\widetilde{g}_{\gamma}, \tilde{g}_{\beta}, \tilde{g}_{\gamma}^{*}, \tilde{g}_{\beta}^{*}\right)$ denote the associated vector of government spending. The equilibrium tax 
rates are characterized by the following conditions

$$
\begin{array}{r}
\pi\left[V^{\prime}\left(\widetilde{c}_{\gamma}\right) y^{m}(1+\varepsilon)-W^{\prime}\left(\widetilde{g}_{\gamma}\right) \bar{y}(1+\varepsilon)\right]-\frac{(1-\pi) V^{\prime}\left(\widetilde{c}_{\beta}\right) \widetilde{x}_{\gamma} \frac{\partial \widetilde{P}(\widetilde{t})}{\partial t_{\gamma}}}{(\widetilde{P}(\widetilde{t}))^{2}}=0 \\
(1-\pi)\left[V^{\prime}\left(\widetilde{c}_{\beta}\right) y^{m}(1-\varepsilon)-W^{\prime}\left(\widetilde{g}_{\beta}\right) \bar{y}(1-\varepsilon)\right]-\frac{(1-\pi) V^{\prime}\left(\widetilde{c}_{\beta}\right) \widetilde{x}_{\gamma} \frac{\partial \widetilde{P}(\widetilde{t})}{\partial t_{\beta}}}{(\widetilde{P}(\widetilde{t}))^{2}}=0 \\
\pi\left[V^{\prime}\left(\widetilde{c}_{\gamma}^{*}\right) y^{m}(1-\varepsilon)-W^{\prime}\left(\widetilde{g}_{\gamma}^{*}\right) \bar{y}(1-\varepsilon)\right]-\frac{(1-\pi) V^{\prime}\left(\widetilde{c}_{\beta}^{*}\right) \widetilde{x}_{\gamma}^{*} \frac{\partial \widetilde{P}(\widetilde{t})}{\partial t_{\gamma}^{*}}}{(\widetilde{P}(\widetilde{t}))^{2}}=0 \\
(1-\pi)\left[V^{\prime}\left(\widetilde{c}_{\beta}^{*}\right) y^{m}(1+\varepsilon)-W^{\prime}\left(\widetilde{g}_{\beta}^{*}\right) \bar{y}(1+\varepsilon)\right]-\frac{(1-\pi) V^{\prime}\left(\widetilde{c}_{\beta}^{*}\right) \widetilde{x}_{\gamma}^{*} \frac{\partial \widetilde{P}(\widetilde{t})}{\partial t_{\beta}^{*}}}{(\widetilde{P}(\widetilde{t}))^{2}}=0
\end{array}
$$

To compute the sign of $\frac{\partial \widetilde{P}(t)}{\partial t_{\beta}}, \frac{\partial \widetilde{P}(t)}{\partial t_{\gamma}}, \frac{\partial \widetilde{P}(t)}{\partial t_{\gamma}^{*}}$ and $\frac{\partial \widetilde{P}(t)}{\partial t_{\beta}^{*}}$, let $z_{\gamma}\left(t_{\gamma}, t_{\beta}, t_{\gamma}^{*}, t_{\beta}^{*}, P\right)$ denote the aggregate demand function for security $\gamma$ and totally differentiate the equilibrium condition

$$
z_{\gamma}\left(t_{\gamma}, t_{\beta}, t_{\gamma}^{*}, t_{\beta}^{*}, P\right)=0
$$

with respect to $P$ and $t_{\gamma}, t_{\beta}, t_{\gamma}^{*}$ and $t_{\beta}^{*}$ respectively. For West we get

$$
\begin{aligned}
\frac{\partial \widetilde{P}\left(\tilde{t}_{\gamma}, \tilde{t}_{\beta}, \widetilde{t}_{\gamma}^{*}, \widetilde{t}_{\beta}^{*}\right)}{\partial t_{\gamma}} & =-\frac{\frac{\partial z_{\gamma}\left(t_{\gamma}, t_{\beta}, t_{\gamma}^{*}, t_{\beta}^{*}, P\right)}{\partial t_{\gamma}}}{\frac{\partial z_{\gamma}\left(t_{\gamma}, t_{\beta}, t_{\gamma}^{*}, t_{\beta}^{*}, P\right)}{\partial P}} \\
\frac{\partial \widetilde{P}\left(\widetilde{t}_{\gamma}, \widetilde{t}_{\beta}, \widetilde{t}_{\gamma}^{*}, \widetilde{t}_{\beta}^{*}\right)}{\partial t_{\beta}} & =-\frac{\frac{\partial z_{\gamma}\left(t_{\gamma}, t_{\beta}, t_{\gamma}^{*}, t_{\beta}^{*}, P\right)}{\partial t_{\beta}}}{\frac{\partial z_{\gamma}\left(t_{\gamma}, t_{\beta}, t_{\gamma}^{*}, t_{\beta}^{*}, P\right)}{\partial P}}
\end{aligned}
$$

Since by definition

$$
z_{\gamma}\left(t_{\gamma}, t_{\beta}, t_{\gamma}^{*}, t_{\beta}^{*}, P\right)=\int\left[x_{\gamma}\left(t_{\gamma}, t_{\beta}, P, y\right)+x_{\gamma}^{*}\left(t_{\gamma}^{*}, t_{\beta}^{*}, P, y\right)\right] d G(y)
$$

we have

$$
\begin{aligned}
& \frac{\partial z_{\gamma}\left(t_{\gamma}, t_{\beta}, t_{\gamma}^{*}, t_{\beta}^{*}, P\right)}{\partial t_{\gamma}}=\int \frac{\partial x_{\gamma}\left(t_{\gamma}, t_{\beta}, P, y\right)}{\partial t_{\gamma}} d G(y) \\
& \frac{\partial z_{\gamma}\left(t_{\gamma}, t_{\beta}, t_{\gamma}^{*}, t_{\beta}^{*}, P\right)}{\partial t_{\beta}}=\int \frac{\partial x_{\gamma}\left(t_{\gamma}, t_{\beta}, P, y\right)}{\partial t_{\beta}} d G(y)
\end{aligned}
$$

and from the first order conditions

$$
V^{\prime}\left(y(1-\varepsilon)\left(1-t_{\beta}\right)-\frac{x_{\gamma}}{P}\right)-\frac{P \pi}{1-\pi} V^{\prime}\left(y(1+\varepsilon)\left(1-t_{\gamma}\right)+x_{\gamma}\right)=0
$$




$$
V^{\prime}\left(y^{m}(1+\varepsilon)\left(1-t_{\beta}^{*}\right)-\frac{x_{\gamma}^{*}}{P}\right)-\frac{P \pi}{1-\pi} V^{\prime}\left(y^{m}(1-\varepsilon)\left(1-t_{\gamma}^{*}\right)+x_{\gamma}^{*}\right)=0
$$

we get

$$
\begin{aligned}
& \frac{\partial x_{\gamma}\left(t_{\gamma}, t_{\beta}, P, y\right)}{\partial t_{\gamma}}=\frac{P \pi}{1-\pi}(1+\varepsilon) \frac{V^{\prime \prime}\left(\widetilde{c}_{\gamma}, y\right) y}{\frac{V^{\prime \prime}\left(\widetilde{c}_{\beta}, y\right)}{P}+V^{\prime \prime}\left(\widetilde{c}_{\gamma}, y\right) \frac{P \pi}{1-\pi}}>0 \\
& \frac{\partial x_{\gamma}\left(t_{\gamma}, t_{\beta}, P, y\right)}{\partial t_{\beta}}=-(1-\varepsilon) \frac{V^{\prime \prime}\left(\widetilde{c}_{\beta}, y\right) y}{\frac{V^{\prime \prime}\left(\widetilde{c}_{\beta}, y\right)}{P}+V^{\prime \prime}\left(\widetilde{c}_{\gamma}, y\right) \frac{P \pi}{1-\pi}}<0
\end{aligned}
$$

which imply that

$$
\begin{aligned}
& \frac{\partial z_{\gamma}\left(t_{\gamma}, t_{\beta}, t_{\gamma}^{*}, t_{\beta}^{*}, P\right)}{\partial t_{\gamma}}=\frac{P \pi}{1-\pi}(1+\varepsilon) \int \frac{V^{\prime \prime}\left(\widetilde{c}_{\gamma}, y\right) y}{\frac{V^{\prime \prime}\left(\widetilde{c}_{\beta}, y\right)}{P}+V^{\prime \prime}\left(\widetilde{c}_{\gamma}, y\right) \frac{P \pi}{1-\pi}} d G(y)>0 \\
& \frac{\partial z_{\gamma}\left(t_{\gamma}, t_{\beta}, t_{\gamma}^{*}, t_{\beta}^{*}, P\right)}{\partial t_{\beta}}=-(1-\varepsilon) \int \frac{V^{\prime \prime}\left(\widetilde{c}_{\beta}, y\right) y}{\frac{V^{\prime \prime}\left(\widetilde{c}_{\beta}, y\right)}{P}+V^{\prime \prime}\left(\widetilde{c}_{\gamma}, y\right) \frac{P \pi}{1-\pi}} d G(y)<0
\end{aligned}
$$

Given Assumption 1 implies that preferences over lotteries of private consumption are homothetic, $\frac{\partial z_{\gamma}\left(t_{\gamma}, t_{\beta}, t_{\gamma}^{*}, t_{\beta}^{*}, P\right)}{\partial P}>0$, for both the West and the East and a unique equilibrium price exists, $\widetilde{P}\left(t_{\gamma}, t_{\beta}, t_{\gamma}^{*}, t_{\beta}^{*}\right)$ with

$$
\frac{\partial \widetilde{P}\left(t_{\gamma}, t_{\beta}, t_{\gamma}^{*}, t_{\beta}^{*}\right)}{\partial t_{\gamma}}<0 \text { and } \frac{\partial \widetilde{P}\left(t_{\gamma}, t_{\beta}, t_{\gamma}^{*}, t_{\beta}^{*}\right)}{\partial t_{\beta}}>0
$$

In a similar way it can be shown that

$$
\frac{\partial \widetilde{P}\left(t_{\gamma}, t_{\beta}, t_{\gamma}^{*}, t_{\beta}^{*}\right)}{\partial t_{\gamma}^{*}}<0 \text { and } \frac{\partial \widetilde{P}\left(t_{\gamma}, t_{\beta}, t_{\gamma}^{*}, t_{\beta}^{*}\right)}{\partial t_{\beta}^{*}}>0
$$

Now suppose that $\widetilde{x}_{\gamma}\left(t_{\gamma}, t_{\beta}, t_{\gamma}^{*}, t_{\beta}^{*}, y^{m}\right)<0$; then from $(24)-(27)$, necessary conditions for equilibrium are

$$
\begin{aligned}
V^{\prime}\left(\widetilde{c}_{\gamma}\right) y^{m}-W^{\prime}\left(\widetilde{g}_{\gamma}\right) \bar{y} & >0 \\
V^{\prime}\left(\widetilde{c}_{\beta}\right) y^{m}-W^{\prime}\left(\widetilde{g}_{\beta}\right) \bar{y} & <0 \\
V^{\prime}\left(\widetilde{c}_{\gamma}^{*}\right) y^{m}-W^{\prime}\left(\widetilde{g}_{\gamma}^{*}\right) \bar{y} & <0 \\
V^{\prime}\left(\widetilde{c}_{\beta}^{*}\right) y^{m}-W^{\prime}\left(\widetilde{g}_{\beta}^{*}\right) \bar{y} & >0
\end{aligned}
$$

Even though we cannot determine the equilibrium price $\widetilde{P}(\widetilde{t})$, we will show that for all values that it could get we would have $\tilde{g}_{\gamma} \geq \tilde{g}_{\beta}$ and $\tilde{g}_{\gamma}^{*} \leq \tilde{g}_{\beta}^{*}$.

1. If $\widetilde{P}(\tilde{t})=\frac{1-\pi}{\pi}$, this implies that $\widetilde{c}_{\gamma}=\widetilde{c}_{\beta}$ and $\tilde{c}_{\gamma}^{*}=\widetilde{c}_{\beta}^{*}$, then from (32)-(35) we have $\tilde{g}_{\gamma} \geq \tilde{g}_{\beta}$ and $\widetilde{g}_{\gamma}^{*} \leq \widetilde{g}_{\beta}^{*}$. 
2. If $\widetilde{P}(\widetilde{t})>\frac{1-\pi}{\pi}$, this implies that $\widetilde{c}_{\gamma}>\widetilde{c}_{\beta}$ and $\widetilde{c}_{\gamma}^{*}>\widetilde{c}_{\beta}^{*}$. Inequalities (32) and (33) then imply that $\widetilde{g}_{\gamma} \geq \widetilde{g}_{\beta}$, and for $\widetilde{P}(\widetilde{t})>\frac{1-\pi}{\pi}$ to be part of an equilibrium, the aggregate net endowment in state $\beta$ must be less than aggregate net endowment in state $\gamma$, that is, $\tilde{g}_{\beta}^{*}+\widetilde{g}_{\beta}>\tilde{g}_{\gamma}^{*}+\widetilde{g}_{\gamma}$ which implies that $\tilde{g}_{\gamma}^{*} \leq \tilde{g}_{\beta}^{*}$.

3. If $\widetilde{P}(\tilde{t})<\frac{1-\pi}{\pi}$, this implies that $\widetilde{c}_{\gamma}<\widetilde{c}_{\beta}$ and $\widetilde{c}_{\gamma}^{*}<\widetilde{c}_{\beta}^{*}$. Inequalities (34) and (35) then imply that $\widetilde{g}_{\gamma}^{*} \leq \widetilde{g}_{\beta}^{*}$, and for $\widetilde{P}(\widetilde{t})<\frac{1-\pi}{\pi}$ to be an equilibrium, the aggregate net endowment in state $\beta$ must be greater than aggregate net endowment in state $\gamma$, that is, $\tilde{g}_{\beta}^{*}+\widetilde{g}_{\beta}<\tilde{g}_{\gamma}^{*}+\tilde{g}_{\gamma}$ which implies that $\tilde{g}_{\gamma} \geq \tilde{g}_{\beta}$.

A similar argument shows that assuming that $\widetilde{x}_{\gamma}\left(t_{\gamma}, t_{\beta}, t_{\gamma}^{*}, t_{\beta}^{*}, y^{m}\right) \geq 0$ leads to a contradiction.

\section{B.4 Proof of Proposition 3}

Assumption 1 guarantees that the allocations of the equilibrium of the risk sharing game are interior. This implies that expected equilibrium payoffs are continuous in $\pi$ and it is sufficient to show the claim when $\pi=1 / 2$.

If regions are ex-ante identical, $\pi=1 / 2$, by symmetry $\tilde{g}_{\beta}^{*}=\tilde{g}_{\gamma}$ and $\tilde{g}_{\gamma}^{*}=\tilde{g}_{\beta}$, which implies that $\widetilde{P}(t)=1$ and therefore $\widetilde{c}_{\gamma}=\widetilde{c}_{\beta}=\widetilde{c}_{\gamma}^{*}=\widetilde{c}_{\beta}^{*}=\widetilde{c}$. When fiscal policies are set after trading in securities, in equilibrium $\widehat{c}_{\gamma}=\widehat{c}_{\beta}=\widehat{c}_{\gamma}^{*}=\widehat{c}_{\beta}^{*}=\widehat{c}$ and $\widehat{g}_{\beta}^{*}=\widehat{g}_{\beta}=\widehat{g}_{\gamma}=\widehat{g}_{\gamma}=\widehat{g}$. Then the statement of the proposition is equivalent to $\widehat{c}>\widetilde{c}$.

Since $\widetilde{c}_{\gamma}=\widetilde{c}_{\beta}=\widetilde{c}_{\gamma}^{*}=\widetilde{c}_{\beta}^{*}=\widetilde{c}$ then from (28), (29), (30) and (31) we get

$$
\begin{aligned}
& \frac{\partial \widetilde{P}\left(\tilde{t}_{\gamma}, \tilde{t}_{\beta}, \widetilde{t}_{\gamma}^{*}, \tilde{t}_{\beta}^{*}\right)}{\partial t_{\gamma}}=-\frac{\int \frac{y(1+\varepsilon)}{2} d G(y)}{\frac{\partial z_{\gamma}\left(\widetilde{t}_{\gamma}, \widetilde{t}_{\beta}, \widetilde{t}_{\gamma}^{*}, \widetilde{t}_{\beta}^{*}, \widetilde{P}\right)}{\partial P}} \\
& \frac{\partial \widetilde{P}\left(\widetilde{t}_{\gamma}, \widetilde{t}_{\beta}, \widetilde{t}_{\gamma}^{*}, \widetilde{t}_{\beta}^{*}\right)}{\partial t_{\beta}}=\frac{\int \frac{y(1-\varepsilon)}{2} d G(y)}{\frac{\partial z_{\gamma}\left(\widetilde{t}_{\gamma}, \widetilde{t}_{\beta}, \widetilde{t}_{\gamma}^{*}, \widetilde{t}_{\beta}^{*}, \widetilde{P}\right)}{\partial P}}
\end{aligned}
$$

and substituting these into (24) and (25) we get

$$
\begin{aligned}
& W^{\prime}\left(\widetilde{g}_{\gamma}\right) \bar{y}=V^{\prime}(\widetilde{c})\left[y^{m}+\frac{\frac{1}{2} \widetilde{x}_{\gamma} \bar{y}}{\frac{\partial z_{\gamma}\left(\widetilde{t}_{\gamma}, \widetilde{t}_{\beta}, \widetilde{t}_{\gamma}, \widetilde{t}_{\beta}^{*}, \widetilde{P}\right)}{\partial P}}\right] \\
& W^{\prime}\left(\widetilde{g}_{\beta}\right) \bar{y}=V^{\prime}(\widetilde{c})\left[y^{m}-\frac{\frac{1}{2} \widetilde{x}_{\gamma} \bar{y}}{\frac{\partial z_{\gamma}\left(\widetilde{t}_{\gamma}, \widetilde{t}_{\beta}, \widetilde{t}_{\gamma}^{*}, \widetilde{t}_{\beta}^{*}, \widetilde{P}\right)}{\partial P}}\right]
\end{aligned}
$$

which imply that

$$
W^{\prime}\left(\tilde{g}_{\gamma}\right) \bar{y}-V^{\prime}(\widetilde{c}) y^{m}=V^{\prime}(\widetilde{c}) y^{m}-W^{\prime}\left(\tilde{g}_{\beta}\right) \bar{y}
$$


We know that $V^{\prime}(\widehat{c})=W^{\prime}(\widehat{g}) \frac{\bar{y}}{y^{m}}$. Now, suppose contrary to the claim that $\widehat{c} \leq \widetilde{c}$. By concavity of $V($.$) , this implies that V^{\prime}(\widehat{c}) \geq V^{\prime}(\widetilde{c})$ and this together with (36) implies that

$$
\bar{y}\left[W^{\prime}\left(\widetilde{g}_{\gamma}\right)+W^{\prime}\left(\widetilde{g}_{\beta}\right)\right]=2 y^{m} V^{\prime}(\widetilde{c}) \leq 2 y^{m} V^{\prime}(\widehat{c})=2 \bar{y} W^{\prime}(\widehat{g})
$$

which in turn implies that

$$
W^{\prime}\left(\widetilde{g}_{\gamma}\right)+W^{\prime}\left(\widetilde{g}_{\beta}\right) \leq 2 W^{\prime}(\widehat{g})
$$

From Proposition $2 \tilde{g}_{\gamma}>\tilde{g}_{\beta}$ and this implies that at least one of $\tilde{g}_{\gamma} \neq \hat{g}, \tilde{g}_{\beta} \neq \hat{g}$ holds. Given $W^{\prime \prime \prime}()>0,. W^{\prime}($.$) is convex and the previous result implies that$

$$
\begin{aligned}
& W^{\prime}\left(\tilde{g}_{\gamma}\right) \geq W^{\prime}(\hat{g})+W^{\prime \prime}(\hat{g})\left(\tilde{g}_{\gamma}-\hat{g}\right) \\
& W^{\prime}\left(\widetilde{g}_{\beta}\right) \geq W^{\prime}(\hat{g})+W^{\prime \prime}(\hat{g})\left(\tilde{g}_{\beta}-\hat{g}\right)
\end{aligned}
$$

with at least one of the two inequalities holding strictly. Adding (38) and (39) we get

$$
W^{\prime}\left(\widetilde{g}_{\gamma}\right)+W^{\prime}\left(\widetilde{g}_{\beta}\right)-2 W^{\prime}(\widehat{g})>W^{\prime \prime}(\widehat{g})\left(\widetilde{g}_{\gamma}+\widetilde{g}_{\beta}-2 \widehat{g}\right)
$$

From $(37)$ we know that $W^{\prime}\left(\tilde{g}_{\gamma}\right)+W^{\prime}\left(\tilde{g}_{\beta}\right)-2 W^{\prime}(\hat{g}) \leq 0$ which implies that

$$
W^{\prime \prime}(\widehat{g})\left(\widetilde{g}_{\gamma}-\hat{g}+\tilde{g}_{\beta}-\hat{g}\right)<0
$$

Since $W^{\prime \prime}(\widehat{g}) \leq 0$ then $\tilde{g}_{\gamma}+\widetilde{g}_{\beta}>2 \widehat{g}$, and this implies that $\widehat{c}>\widetilde{c}$ leading to a contradiction.

\section{B.5 Proof of Proposition 4}

Part 1. Assumption 1 guarantees that the allocations of the equilibrium of the risk sharing game are interior. This implies that expected equilibrium payoffs are continuous in $\pi$ and it is sufficient to show that when $\pi=1 / 2$ at least half of the residents of each region strictly prefers the fiscal union to the decentralized system. Given $V($.$) is homogeneous of degree 1+r$, the only source of heterogeneity among individuals is the parameter $y^{1+r}$, which enters linearly in individual preferences over policies. The argument used in the Proof of Lemma 1 clarifies that, if the individual with median type strictly prefers the fiscal union to the decentralized system, at least half of the resident of the same region prefer the fiscal union to the decentralized system. This in turn implies that to prove the claim it suffices to show that when $\pi=1 / 2$ the individual with median type in each region strictly prefer the fiscal union to the decentralized system.

When $\pi=1 / 2$, the equilibrium with the fiscal union replicates the equilibrium of the benchmark game. To see this, note that in the fiscal union private consumption and public consumption do not vary across states of nature (as in the equilibrium of the decentralized benchmark game). 
Moreover, $\pi=1 / 2$ implies that the distribution of expected endowment is identical across regions, so that the median type individuals' most preferred tax rate (and government spending) are identical and this proves that the fiscal union is identical to the decentralized system (without distortions).

We now show that median type residents of the West and the East strictly prefer to equilibrium of the benchmark game to the equilibrium of the manipulation game.

Suppose the opposite is true. From Proposition 1 we know that in the equilibrium of the benchmark game

$$
\begin{aligned}
\hat{c}_{\gamma}\left(y^{m}\right) & =\widehat{c}_{\beta}\left(y^{m}\right) \\
\hat{g}_{\gamma} & =\widehat{g}_{\beta} .
\end{aligned}
$$

From Proposition 2 we know that when $\pi=1 / 2$, in the equilibrium of the manipulation game

$$
\begin{gathered}
\widetilde{c}_{\gamma}\left(y^{m}\right)=\widetilde{c}_{\beta}\left(y^{m}\right) \\
\widetilde{g}_{\gamma}>\widetilde{g}_{\beta} .
\end{gathered}
$$

Consider now the following government expenditure vector

$$
\tilde{\widetilde{g}}_{\gamma}=\tilde{\widetilde{g}}_{\beta}=\frac{\tilde{g}_{\gamma}+\tilde{g}_{\beta}}{2}
$$

Given by Assumption $1 W^{\prime \prime}()<$.0 , the median type resident of the West strictly prefers allocation $\left(\widetilde{c}_{\gamma}\left(y^{m}\right), \widetilde{c}_{\beta}\left(y^{m}\right), \widetilde{\tilde{g}}_{\gamma}, \widetilde{\widetilde{g}}_{\beta}\right)$ to $\left(\widetilde{c}_{\gamma}\left(y^{m}\right), \tilde{c}_{\beta}\left(y^{m}\right), \tilde{g}_{\gamma}, \tilde{g}_{\beta}\right)$. Consider now the following two cases:

1. $\widetilde{\widetilde{g}}_{\gamma}=\widetilde{\widetilde{g}}_{\beta}=\hat{g}_{\gamma}=\hat{g}_{\beta}$. In this case a contradiction arises to the hypothesis that the median type individual prefers the equilibrium of the manipulation game to the equilibrium of the benchmark game.

2. $\widetilde{\widetilde{g}}_{\gamma}=\widetilde{\widetilde{g}}_{\beta} \neq \widehat{g}_{\gamma}=\widehat{g}_{\beta}$. In this case a contradiction arises to the hypothesis that $\left(\hat{g}_{\gamma}, \widehat{g}_{\beta}\right)$ is part of the equilibrium of the benchmark game, as the median type individual strictly prefers the equilibrium with $\left(\widetilde{\widetilde{g}}_{\gamma}, \widetilde{\widetilde{g}}_{\beta}\right)$.

Part 2. By the same arguments as above, to prove the claim it suffices to show that when $\pi=1$ the individual of the West with median type strictly prefers the decentralized system over the fiscal union and the individual of the East with median type strictly prefers the fiscal union to the decentralized system.

When $\pi=1$, no uncertainty exists and there is no gain in risk sharing in moving from a decentralized system to a fiscal union (because there is no need for risk sharing). Suppose the fiscal union and the decentralized manipulation game lead to the same equilibrium tax rates. 
Given fiscal policy is nondiscriminatory, this would imply a lower level of government consumption for Western residents in the fiscal union than in the decentralized system and in turn that the Western resident with median type would prefer the latter to the former. Suppose now the fiscal union and the decentralized system lead to the different equilibrium tax rates and consider the three following situations: a) Fiscal policy in the West is the decentralized manipulation game equilibrium tax rate; b) Fiscal policy in the West is the fiscal union equilibrium tax rate; c) Fiscal policy in the fiscal union is the fiscal union equilibrium tax rate. We want to show that the Western resident with median type prefers (a) to (c), while (b) is a hypothetical situation we consider for convenience. It is easy to see that by revealed preferences the median type Western resident prefers (a) to (b). It is also easy to see that given fiscal policy is nondiscriminatory disposable income for Western residents under (b) and (c) is the same but government consumption is lower in (c) than in (b). This implies that the Western resident with median type prefers (b) to (c) and ultimately proves that he prefers (a) to (c). 
[1] Alesina, R. and R. Perotti (1995) "Economic Risk and Political Risk in Fiscal Unions", NBER working paper 4992.

[2] Arrow, K. J. (1964) "The Role of the Securities on the Optimal Allocations of Risk Bearing", Review of Economic Studies, 31, 91-96.

[3] Atkinson, A. B. and J. E. Stiglitz (1987) Lectures on Public Economics, McGraw-Hill International Edition, London, UK.

[4] Devereux, M.B. and K.M. Lee (1999) "Endogenous Trade Policy and the Gains from International Financial Markets," Journal of Monetary Economics, 43, 35-99.

[5] Grandmont, J. M. (1978) "Intermediate Preferences and the Majority Rule", Econometrica, $46,317-330$.

[6] Kreps, D. (1982) "Multiperiod Securities and the Efficient Allocation of Risk: A Comment on the Black-Scholes Option Pricing Model", in J. McCall (ed.) The Economics of Uncertainty and Information, Chicago University Press, Chicago, 203-232.

[7] Persson, T. and G. Tabellini (1995) "Double-Edged Incentives: Institutions and Policy Coordination," in: G.M. Grossman and K. Rogoff (eds.) Handbook of International Economics, volume 3, Elsevier North-Holland, Amsterdam, 1913-71.

[8] Persson, T. and G. Tabellini (1996a) "Federal Fiscal Constitutions: Risk-Sharing and Redistribution", Journal of Political Economy, 104, No 51.

[9] Persson, T. and G. Tabellini (1996b) "Federal Fiscal Constitutions: Risk Sharing and Moral Hazard", Econometrica, 64, No. 3, 623-646. 